\title{
TRES CUESTIONES SOBRE LA EXCEPCIÓN DE LITISPENDENCIA EN EL PROCESO CIVIL CHILENO
}

[Three aspects of the Exception of the Litis Pendentia in the Chilean Civil Process]

\author{
Ignacio Ried UndurRaga* \\ Universidad Diego Portales, Santiago, Chile
}

\begin{abstract}
RESUMEN
El trabajo trata tres puntos referidos a la excepción dilatoria de litispendencia en el proceso civil chileno. El primer es si es a figura corresponde a un remedio para el concurso de acciones y de normas. El segundo de ellas se refiere a su finalidad, vinculada con los deberes de buena fe y la teoría de los actos propios. El tercero propone que esta excepción abarca no sólo los casos en que exista perfecta identidad entre dos o más procesos, sino también
\end{abstract}

\begin{abstract}
This article addresses three points regarding the exception of the Litis pendentia in the Chilean Civil Process. The first one questions whether this legal construct is a remedy for the merging of actions and regulations. The second one refers to its aim, which is linked to the duties of good faith and the theory of the estoppel. The third point proposes that this exception not only addresses cases with a perfect identity between two
\end{abstract}

RECIBIDO el 18 de junio y ACEPTADO el 7 de diciembre de 2015

* Licenciado en derecho por la Pontificia Universidad Católica de Chile; magíster en derecho penal y ciencias penales por la Universidad de Barcelona y Universidad Pompeu Fabra, Barcelona, España. Profesor del curso de litigación y estrategia civil en la Facultad de Derecho de la Universidad Diego Portales. Dirección postal: Av. Andrés Bello 2711, piso 8, Las Condes, Santiago. Correo electrónico: iried@uc.cl 
aquellos casos de procesos conexos y en que uno es prejudicial a otro.

\section{Palabras clave}

Litispendencia - Acumulación de acciones - Buena fe procesal - Conexión de procesos - Prejudicialidad. or more processes, but also those cases with connected processes in which one is given priority ruling before the other.

\section{KEYWORDS}

Litis Pendentia - Legal Actions being Merged - Procedural Good Faith - Connection of Processes - Pretrial.

\section{LAS TRES CUESTIONES DE LA LITISPENDENCIA DE QUE SE TRATA EN ESTE}

La litispendencia ${ }^{1}$, recogida en nuestro derecho positivo como una de las excepciones dilatorias del juicio ordinario de mayor cuantía en el Código de Procedimiento Civil (artículo $303 \mathrm{~N}^{\circ}$ 3) y una de las excepciones a la ejecución dentro del juicio ejecutivo (artículo $464 \mathrm{~N}^{\circ} 3$ ) es una de las instituciones procesales más interesantes, más relevantes en la práctica y sobre las que menos se ha escrito e investigado. Para el demandado que enfrenta varios litigios idénticos o similares, y para el tribunal que quiere dar una tramitación justa y ordenada, la litispendencia es una institución crucial. Como contrapartida, esta excepción puede ser un serio dolor de cabeza para el demandante que ha intentado procesos idénticos o al menos similares frente a un demandado atento y diestro en el arte de litigar.

En este trabajo intentaré dar respuesta, dentro de las limitaciones de un artículo científico, a tres cuestiones que atañen a esta excepción, y que suelen ser omitidas o malentendidas en la poca doctrina que existe.

La primera de ellas se refiere a si la litispendencia es efectivamente un remedio (procesal) para el denominado concurso de acciones o de normas. La litispendencia no sólo ha sido tratada en forma independiente -enmarcada en las excepciones dilatorias del juicio ordinario y las excepciones a

${ }^{1}$ La voz "litispendencia" puede emplearse en un sentido amplio y restringido. En su sentido amplio, Málaga, Francisco, La litispendencia (Barcelona, J. M. Bosch Editor, 1999), p. 38, dice que se trata del "conjunto de efectos procesales, legalmente previstos a favor de una o ambas partes, que se manifiestan durante la pendencia de un juicio con el objetivo de garantizar la eficacia de la futura definición judicial desde la perspectiva de la duración de dicho juicio, evitando que esta duración perjudique al derecho a tutela judicial efectiva". Se trata de una "ficción de inmutabilidad", de forma tal que las partes no resulten perjudicadas por los cambios ocurridos en distintas realidades ajenas al proceso, mientras dura éste. En este trabajo sólo se abarcará la litispendencia en su sentido restringido, como excepción procesal, y más concretamente, en el juicio ordinario. 
la ejecución- sino también como la solución a un aparente problema de mayor alcance, como es la existencia de los concursos de acciones y de normas. Como se intentará sostener en este trabajo, el propósito de la litispendencia no es solucionar ese problema, el que de cualquier forma es más aparente que real.

La segunda cuestión está vinculada a la primera, y dice relación con tratar de dilucidar cuál es la finalidad de la litispendencia. Como sostendré, el fin de esta institución no es solamente el evitar juicios inútiles, duplicidad de juicios, o sentencias contradictorias, sino sobre todo resguardar la buena fe procesal, en relación a la doctrina de los actos propios, y servir de desincentivo frente a prácticas inescrupulosas o fraudulentas en el proceso.

La tercera y última cuestión a tratar se refiere al alcance de la sentencia que acoge esta excepción; en particular, si solamente abarca los casos en que el segundo juicio iniciado es perfectamente idéntico al primero, o su efecto se extiende a casos conexos. Cosa juzgada, litispendencia y acumulación de autos son tres instituciones conectadas, que descansan sobre la misma premisa, como es la existencia de dos o más procesos similares o idénticos. Sin embargo, tanto la cosa juzgada como la litispendencia han estado rodeadas de un "mito" como es que para su concurrencia es necesaria una estricta identidad legal de partes, cosa pedida y causa de pedir. En esta investigación se explorará una postura diferente: admitir que puede ser procedente la litispendencia en casos en que no exista una perfecta triple identidad legal, sino sólo ciertos elementos comunes entre el primer y el segundo proceso. Como se dirá, en estos casos de "litispendencia por conexidad" y por "prejudicialidad", la acumulación de autos -la alternativa por excelencia a la litispendencia- no será la respuesta idónea para todos aquellos casos en que el verdadero y real "bien de la vida" buscado por el demandante sea exactamente el mismo en ambos procesos, sin perjuicio de que no coincidan la cosa pedida, la causa de pedir y ni siquiera los sujetos.

Antes de tratar estos tres temas, será necesario hacer un breve repaso del tratamiento que se le ha dado a la litispendencia en la ley, la doctrina y la jurisprudencia chilena.

\section{LEY, DOCTRINA Y JURISPRUDENCIA CHILENAS}

La litispendencia está tratada en forma muy escueta en la ley procesal civil chilena. Se alude a ella a propósito de las excepciones dilatorias ${ }^{2}$ en

\footnotetext{
${ }^{2}$ Maturana, Cristián, Relación entre la litispendencia, la acumulación de autos y la cosa juzgada (Memoria para optar al grado de licenciado en ciencias jurídicas y sociales de la U. de Chile, 1982), p. 35 señala que la litispendencia estaría catalogada incorrectamente como una excepción dilatoria, tendiente a corregir los vicios del
} 
el juicio ordinario (artículo 303 № 3 CPC.), de las excepciones anómalas (aquellas dilatorias que se pueden oponer durante prácticamente todo el proceso, incluso en segunda instancia: artículo 305 CPC.) y como una excepción a la ejecución (artículo $464 \mathrm{~N}^{\circ} 3$, sólo respecto de nuevas demandas ejecutivas iniciadas por el ejecutante, como es natural). También el Código de Derecho Internacional Privado la contempla, aunque no será materia de este trabajo ${ }^{3}$. En ninguno de estos preceptos se la define, sino que sólo se la enuncia, posible herencia de la Ley de Enjuiciamiento Civil española de 1881, que tampoco la definía. Esta ausencia de definición, lejos de ser un descuido, parece ser una decisión deliberada tanto del legislador peninsular como chileno, quienes estimaron innecesario un esfuerzo adicional definir un instituto que parece obvio, como es aquel que impide que se sustancien dos juicios en paralelo sobre la misma cosa. Esta simplicidad de la litispendencia es lo que explica su escasa armonización con el alambicado problema del concurso de acciones y de normas, como se verá más adelante.

Entonces, tenemos que la litispendencia es una creación eminentemente doctrinaria y jurisprudencial. La doctrina de los manuales de derecho procesal, que en buenas cuentas son los textos más consultados por estudiantes, abogados y jueces, suele tratarla en forma muy breve, dejando en la oscuridad aspectos importantes.

Mario Casarino adhiere a la tesis mayoritaria de que debe existir perfecta identidad legal entre los dos juicios, esto es, cosa pedida, causa de pedir y

proceso, según se define a esa categoría. En mi opinión -más allá de lo relevante o no que pueda ser esta discusión- la litispendencia sí es una excepción dilatoria; lo que sucede es que tiene efectos permanentes (o semi permanentes, según la teoría que se siga) en el proceso, igual como sucede con la incompetencia; no es casualidad que para el propio Maturana ambas excepciones estén estrechamente relacionadas, y que sea un caso de "incompetencia especial". Y es bien claro que sí corrige un aspecto netamente procesal o adjetivo, como es la competencia del tribunal que seguirá conociendo del asunto. Málaga, cit. (n. 1), pp. 279-283, en lo referido al derecho español señala que históricamente, las leyes procesales españolas habían considerado a la litispendencia como una excepción "de un género distinto", mientras que la doctrina, y las Leyes de Enjuiciamiento de 1855 y 1881, por el contrario, la han catalogado como dilatoria. He dicho que la utilidad de esta discusión es discutible, la que el Código chileno permite oponer la litispendencia no sólo como dilatoria, sino como excepción anómala, en cualquier momento del proceso, incluso en segunda instancia, aunque existe jurisprudencia que ha limitado su alcance en aquellos casos en que, siendo el primer juicio conocido del demandado, éste no la alega sino hasta un momento posterior en el tiempo.

${ }^{3}$ Artículo 394: "La litis pendencia por pleito en otro de los Estados contratantes, podrá alegarse en materia civil cuando la sentencia que se dicte en uno de ellos haya de producir en el otro los efectos de cosa juzgada". 
las partes. Respecto de este último requisito, hace una salvedad y dice que "debe existir identidad legal entre las partes del primer pleito y del segundo, no importando el papel procesal que ellas desempeñen en uno y otro pleito. Se podrá así ser demandante en el primer juicio y demandado en el segundo o viceversa" ${ }^{\text {" }}$. Respecto de los efectos que produce la resolución que acoge esta excepción, este autor se inclina por la paralización del proceso "intertanto se falle el primero por sentencia ejecutoriada; a objeto de que la parte favorecida con la excepción de cosa juzgada, que pueda emanar de esta sentencia, la oponga como excepción perentoria en el segundo pleito, que estaba paralizado, y cuya tramitación ha debido reiniciarse a virtud de la terminación del primero"s. Darío Benavente adscribe también a la teoría de la triple identidad legal, aunque no detalla cuáles son los efectos que esta excepción produce en el proceso $0^{6}$. Ignacio Rodríguez Papic identifica cuatro requisitos de la litispendencia: la existencia de un juicio pendiente, ante el mismo tribunal $\mathrm{u}$ otro diverso, la identidad de partes entre ambos juicios, la identidad de cosa pedida y de causa de pedir. Cita una jurisprudencia de la Corte de Apelaciones de Concepción, de 1928 que exigiría "que sean iguales las acciones entabladas en ambos juicios", aunque no explicita cuál es el preciso efecto de la litispendencia en el proceso, en el caso de ser acogida ${ }^{7}$. Muy interesante resulta el análisis del profesor Carlos Anabalón, quien constata que la litispendencia es "una noción jurídicoprocesal que no se halla definida ni reglamentada en los Códigos, acaso por ser demasiado comprensible y reconocida por la doctrina y a pesar de su concatenación y semejanza con otras instituciones, tales como la incompetencia judicial, la cosa juzgada y la acumulación de autos"8. Este autor repara en que la litispendencia, como "reflejo de la cosa juzgada" exige la misma triple identidad legal entre ambos procesos, razonando -con toda lógica- que será procedente la litispendencia "siempre que la sentencia

${ }^{4}$ Casarino, Mario, Manual de derecho procesal. Derecho procesal civil (Santiago, Editorial Jurídica de Chile, 2009), IV, p. 31.

${ }^{5}$ Ibíd., p. 31.

${ }^{6}$ Benavente, Darío, Derecho procesal civil. Juicio ordinario y recursos procesales $\left(5^{\mathrm{a}}\right.$ edición revisada por Juan Colombo Campbell, Santiago, Editorial Jurídica de Chile, 2004), p. 23.

${ }^{7}$ Rodríguez Papic, Ignacio, Procedimiento civil. Juicio ordinario de mayor cuantía (Santiago, Editorial Jurídica de Chile, 2010), pp. 49-51.

${ }^{8}$ Anabalón, Carlos, Tratado práctico de derecho procesal civil chileno, III: El juicio ordinario de mayor cuantía (Santiago, Arancibia Hermanos, 1963), pp. 148-149. Similares consideraciones se encuentran en el Volumen II del mismo tratado: Disposiciones comunes a todo procedimiento y de las cuestiones de competencia (Escuela Tipográfica Salesiana, Concepción, 1966), a propósito de la excepción e incidente de incompetencia. 
que se dictase en el juicio anterior una vez firme o ejecutoriada, tuviese la virtud de justificar la referida excepción de cosa juzgada dentro del juicio

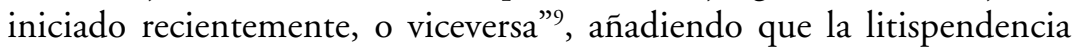
"incompleta” de alguna de las identidades que se exige para cosa juzgada, deviene en la simple acumulación de autos. Anabalón también señala que el efecto de esta excepción, una vez acogida, es el término definitivo del proceso $^{10}$. Alejandro Romero, por su parte, adhiere también al requisito de la triple identidad legal de sujetos, cosa pedida y causa de pedir como antecedente para que proceda la excepción de litispendencia ${ }^{11}$, señalando en otro de sus trabajos sobre la legislación procesal española, que, por ejemplo, los casos de conexidad deben resolverse vía acumulación de autos ${ }^{12}$. Avsolomovich, Lührs y Noguera dicen que la litispendencia, al igual que la incompetencia, suspende definitivamente el desarrollo del proceso, y que en ambos procesos debe existir "una pretensión procesal idéntica" ${ }^{13}$. En términos similares parece pronunciarse la restante doctrina disponible ${ }^{14}$.

No existen monografías recientes publicadas en Chile sobre la litispendencia. Lo más cercano es la exhaustiva tesis de grado del procesalista Cristián Maturana, quien señalaba en 1982, con toda razón, que el criterio de la triple identidad "no puede ser sustentado como un dogma de fe absoluto, sino que debe ser analizado en forma rigurosa cada vez que se presente esta excepción, por cuanto la litispendencia no tiene lugar siempre que aparezca que la sentencia de un pleito deba producir la excepción de cosa

${ }^{9}$ Ibíd., p. 149.

${ }^{10}$ Ibíd., p. 151.

${ }^{11}$ Romero Seguel, Alejandro, Curso de derecho procesal civil (Santiago, Editorial Jurídica de Chile, 2012), p. 79.

${ }^{12}$ Romero Seguel, Alejandro, La acumulación de acciones en el derecho procesal español (Madrid, Cedecs, 1999), p. 185

${ }^{13}$ Avsolomovich, Alex - LÜhrs, Germán - Noguera, Ernesto, Nociones de derecho procesal (Santiago, Editorial Jurídica de Chile, 1966), pp. 100 y 106. Citan estos autores una sentencia de la Corte de Apelaciones de Concepción de 10 de enero de 1934, que resolvió no en apego de la doctrina de la triple identidad legal, sino señalando que si ni siquiera concurría uno de los elementos, pese a lo cual no podía haber litispendencia .

${ }^{14}$ GuZmán Santa CRUZ, Roberto, Repertorio de conceptos de derecho procesal civil (Santiago, Carlos E. Gibbs, 1966), pp. 66-67, cita entre otros a Fernando Alessandri: "se interpone esta excepción dilatoria cuando entre las mismas partes existe pendiente un pleito que versa sobre la misma cuestión”. También cita a Avsolomovich, Lührs y Noguera: "por razones de justicia las legislaciones han reconocido esta figura llamada litispendencia y cuya existencia obsta la eficacia de la pretensión procesal, ya que existiendo ella no se puede decir que el proceso sea adecuado (apropiado o "con propiedad" para una cosa), puesto que ya hay otro que lo es". 
juzgada en otro"15. Este autor advierte que la teoría de la triple identidad no sirve respecto de dos procesos no "integrales", en palabras de Carnelutti, los procesos "que no sirven para componer toda la litis, puesto que no resuelve todas las cuestiones relativas a una de las vocaciones"16. Con cita a Calamandrei, señala Maturana que "no se trata ya, como en los casos de conexión, de una relación entre causas distintas que sólo tengan en común algunos de sus elementos de identificación, sino de una relación entre dos causas idénticas y coincidentes en todos los tres elementos, con la única diferencia que en una de ella (continente) el petitum es más amplio que en la otra (contenida), de modo que comprende, además, algún capítulo de demanda que no se comprende en la otra (en las causas contenidas se discute, por ejemplo, acerca del pago de una de las cuotas de un préstamo; en la continente, acerca de la restitución de la suma entera prestada" ${ }^{17}$, ampliando de esa forma -siquiera tímidamente- el rango de acción de esta excepción dilatoria.

Maturana también se ocupa de los efectos que produce la sentencia que acoge la excepción de litispendencia en el proceso, aspecto que, pese a su importancia, aún no es pacífico en nuestra jurisprudencia y doctrina, y que no está regulado en la ley. En pos de Calamandrei, Maturana cree que el efecto es la terminación definitiva del segundo proceso iniciado, donde se promovió la excepción, descartando que el efecto sea la paralización del segundo proceso mientras no concluya el primero (que entonces causará efecto de cosa juzgada) como también descartando la acumulación ${ }^{18}$. En esto no estoy de acuerdo con Maturana, por lo siguiente. La terminación definitiva del segundo proceso, que de por sí es una solución radical, puede acarrear un perjuicio irreparable al demandante. Los casos de litispendencia

${ }^{15}$ Maturana, cit. (n. 2), p. 58.

${ }^{16}$ Carnelutti, Francesco, Instituciones del proceso civil (Buenos Aires, Ediciones Jurídicas Europa-América, 1950), I, pp. 410-411. En la p. 28, aclara el autor que la litis es "el conflicto (intersubjetivo) de intereses calificado por una pretensión resistida (discutida)"; por su parte, las "cuestiones" son definidas en la p. 36, como "la duda acerca de una razón" que pudo darse tanto en la pretensión (del actor) como en la resistencia del demandado. Una revisión crítica de esta teoría es obra de CALAMANDREI, Piero, Estudios sobre el proceso civil (Santiago, Editorial Bibliográfica Argentina, 1945), pp. 265-294.

${ }^{17}$ Ibíd., p. 151, con cita a CALAMANDREI, Piero, Instituciones de derecho procesal civil (Buenos Aires, EJEA, 1986), II, pp. 214-215.

${ }^{18}$ Ibíd., pp. 61-67, también con cita a Calamandrei. En el mismo sentido se habrían pronunciado Alsina, Hugo, Tratado teórico de derecho procesal civil y comercial (Buenos Aires, Ediar, 1957), II, p. 102; Prieto Castro, Leonardo, Derecho procesal civil (Madrid, Aranzadi, 1982), I, p. 600; y Rosenberg, Leo, Tratado de derecho procesal civil (Buenos Aires, EJEA, 1955), II, p. 125. 
muchas veces obedecen a que el primer proceso adolece de algún vicio que el demandante no puede o no quiere subsanar, lo que motiva la interposición de una segunda demanda sin esperar la terminación del primer juicio. Que el efecto de la litispendencia sea la terminación del segundo proceso puede ocasionar que, si el primer proceso también termina, sin sentencia sobre el fondo, el demandante literalmente no tenga un tribunal competente donde seguir adelante con su acción, y para peor, arriesgando muchas veces la prescripción de la misma. Por lo mismo, es más razonable que el efecto de la litispendencia sea la suspensión del segundo proceso mientras se tramita el primero. Si éste concluye, sin un pronunciamiento sobre el fondo que produzca cosa juzgada, podrá el actor ocurrir ante el segundo juez y seguir adelante con el proceso, ya que el obstáculo que justificó la litispendencia habrá desaparecido ${ }^{19}$. Respecto de la acumulación, hay que decir que la ley chilena la contempla como una institución diferente de la litispendencia, a pesar que también procede en los casos en que existe triple identidad legal. Más adelante en este trabajo me explayaré acerca de los casos en que estimo debiera suspenderse el proceso por litispendencia -cuando exista mala fe del actor- $y$ aquellos en que ambos procesos deben ser acumulados -cuando ello no ocurra ${ }^{20}$.

En el Proyecto de Código Procesal Civil (Boletín 8197-07, de 12 de marzo de 2012) en actual trámite en el Congreso chileno, se contempla, en forma similar a la legislación vigente, la prerrogativa del demandado de oponer la excepción de litispendencia, como una de las "excepciones previas" del artículo 267, la que, previos descargos del demandante, debe ser resuelta por el tribunal en la audiencia preliminar, siguiendo muy de cerca el modelo de la Ley de Enjuiciamiento Civil española 1/2000. Al igual que sucede hoy, el proyecto optó por no definir qué se entiende por litispendencia. El proyecto incorpora una interesante novedad, al permitir que el juez de oficio controle la admisión de la demanda, apreciando de oficio la concurrencia de, entre otras situaciones, la litispendencia (artículo 258); prerrogativa que, a la luz de la experiencia comparada -y como viene

${ }^{19}$ Esta es por lo demás la opinión de CARnelutTi, cit. (n. 16), p. 413, respecto del también ambiguo artículo 39 de la ley procesal civil italiana.

${ }^{20}$ Este problema estaba ya solucionado en la Ley de Enjuiciamiento Civil española de 1855 y 1881, según expresa MálaGA, cit. (n. 1), pp. 284-290, y llama la atención que el Código no la hubiera adoptado. En efecto, la ley procesal española contemplaba expresamente que el efecto de la litispendencia que era acogida era la "absolución de la instancia”, en contraposición al efecto de la acumulación, que permitía la coexistencia conjunta de ambos juicios. En el artículo 421 de la Ley de Enjuiciamiento Civil del año 2000 también se solucionó el problema de la misma forma, o sea, con el sobreseimiento para el caso en que la litispendencia fuere acogida. 
sucediendo en Chile también cuando se conceden este tipo de atribuciones proactivas al juez- suele tener poca o nula aplicación práctica, sobre todo porque el principal interesado en que se acoja la litispendencia (y quien dispondrá de los antecedentes fundantes) será el demandado, y no el juez. Otra innovación interesante, sobre la que me explayaré también más adelante, es que el proyecto establece una clara preferencia de la litispendencia frente a la acumulación, cuando existe perfecta identidad de procesos (artículo 56).

La jurisprudencia chilena, en consistencia con la posición doctrinaria mayoritaria antes expuesta, no se ha hecho mayor problema con este instituto procesal, y en forma constante a lo largo de los años ha recogido la tesis de que es necesaria una estricta triple identidad legal entre el proceso nuevamente promovido y el anterior, lo que en muchísimos casos lleva a que la excepción sea finalmente rechazada. Es decir, ha seguido cómodamente la doctrina mayoritaria "de manuales". Afortunadamente, al ser una de aquellas sentencias que ponen fin al juicio o hacen imposible su continuación, cada cierto tiempo la Corte Suprema tiene la oportunidad de pronunciarse al respecto, cuando el demandante ha sido agraviado con la concesión de la litispendencia. Entre los fallos recientes consultados, está el de la Cuarta Sala de la Corte Suprema de 24 de noviembre de 2008 (rol $\mathrm{N}^{\circ}$ 6153/2008), que resolvió que para que procediera esta excepción "se requiere que exista un pleito pendiente, el que debe ser idéntico al juicio en que se promueve. Dicha identidad corresponde a la regla del artículo 177 del Código de Enjuiciamiento Civil, al estatuir la institución de la cosa juzgada, con la triple identidad copulativa de personas, objeto y causa de pedir, que la excepción en estudio se preocupa de resguardar". La Primera Sala del máximo tribunal, en fallo de 17 de agosto de 2010 (rol N 5222/2010) señaló a su turno que "analizados ambos procesos, es evidente que concurren en la especie la identidad de cosa pedida, es decir, del beneficio jurídico inmediato que se reclama y la identidad de causa de pedir, esto es, el fundamento inmediato del derecho deducido en juicio, y en tales condiciones, tal como sostuvieron los jueces del mérito, confluye en la especie la exigencia de triple identidad prevenida en el artículo 177’. En un fallo de 30 de enero de 2012, la Primera Sala de la Corte Suprema (rol No 2701/2010) dijo que "para que la excepción dilatoria pueda prosperar, se requiere la concurrencia de la misma triple identidad que justifica la excepción de cosa juzgada, en el artículo 177', anulando de esta forma un fallo confirmatorio de la Corte de Apelaciones de Temuco, que había reconocido la litispendencia en un caso de litigios conexos pero no idénticos. Esta es la tendencia jurisprudencial mayoritaria, pero como se expondrá más adelante, la propia Corte Suprema ha debido variar su postura frente a un caso especial de conexidad. 


\section{LA LITISPENDENCIA COMO REMEDIO FRENTE}

Como señalaba al comienzo, la litispendencia es estudiada no sólo como excepción dilatoria en el juicio ordinario -sin perjuicio del escaso material dogmático disponible- sino sobre todo a propósito del llamado concurso de normas y de acciones; en particular, se considera a la litispendencia, junto a otras instituciones, como la acumulación de autos, como un remedio frente a este fenómeno. La litispendencia vendría a solucionar, de esta forma, el "problema" consistente en que unos mismos hechos permitan la invocación de normas sustantivas diversas, y asimismo, el ejercicio de acciones procesales múltiples.

Por lo anterior, se hace imperioso referirse a la teoría de la acumulación de normas y de acciones, y en primer lugar, aunque sea brevemente, a las teorías de la acción, sin la cual no se entiende la de la acumulación de acciones.

\section{Las teorías de la acción.}

Las teorías de la acción fueron las predecesoras de las teorías sobre el objeto del proceso; mientras estas últimas parecían orientadas a un fin práctico, como resolver precisamente los problemas relativos a la cosa juzgada, litispendencia y acumulación, las teorías de la acción aparecen hoy como interesantes ejercicios dogmáticos, aunque inidóneas para proveer materiales que solucionen estos problemas.

Hay que partir diciendo que es en el derecho romano clásico donde fueron creadas las acciones, siglos después recogidas por la pandectística alemana. Álvaro d'Ors definía la acción como "la actuación enderezada a resolver una controversia mediante una decisión definitiva (iudicatum) fundada en la opinión (sententia) de un juez privado" 21 , sistema que inició en la época arcaica con las legis actiones, o sea, "determinados gestos y formas orales que debían tener lugar ante el magistrado", cuyo número "debía ser bastante limitado" 22 y decantó en el procedimiento propiamente formulario, característico de la época clásica, aunque conviviendo ambos por más de un siglo ${ }^{23}$. Respecto del procedimiento formulario, este autor dice que "las fórmulas procesales se caracterizan por su tipicidad: para cada supuesto típico se fue adaptando una fórmula escrita especial. Todo el

\footnotetext{
${ }^{21}$ d'Ors, Álvaro, Derecho privado romano (Pamplona, Ediciones Universidad de Navarra, 1981), p. 111.

${ }^{22}$ Ibíd., p. 113.

${ }^{23}$ Ibíd., p. 117.
} 
derecho clásico depende de esta tipicidad de la fórmula" ${ }^{24}$. Posteriormente el proceso formulario acabó al instaurarse la cognitio extra ordinem, que terminó con la distinción entre las fases in iure y apud iudicem, a partir del siglo III. Como he señalado, esta teoría de la acción fue rescatada por los juristas alemanes del siglo XIX, en particular por Friedrich Karl von Savigny ${ }^{25}$, Bernhard Windscheid ${ }^{26}$ y Theodor Muther ${ }^{27}$, por nombrar sólo

${ }^{24}$ Ibíd., p. 117.

${ }^{25}$ Para Savigny, en la referencia que hace Nieva, Jordi, Derecho procesal, I: Introducción (Madrid, Marcial Pons, 2014), p. 53, "la acción era el derecho en que se transformaba el propio derecho a través de su violación, teniendo la acción una naturaleza similar a la de una obligación”, distinguiendo asimismo entre una acción material y una formal, siendo esta última la única que debía ser materia de estudio del Derecho procesal. En la obra de Marinoni, Luiz Guilherme - Pérez Ragone, Álvaro - NúñEz OjedA, Raúl, Fundamentos del proceso civil. Hacia una teoría de la adjudicación (Santiago, LegalPublishing, 2010), p. 153, se condensa esta idea de Savigny de la siguiente forma: "el derecho de la acción era un derecho resultante de la "transformación", por lo cual el derecho a la tutela nacería después que el derecho material hubiera sido lesionado. De ahí, el motivo por el cual se propuso el concepto de la "metamorfosis" para ilustrar tal situación". Las ideas completas están en VON SAVIGNY, Friedrich, System des heutigen römischen rechts, en Problemgeschichte des Verhältnisses von formellen und materiellem Recht (Berlin, Duncker \& Humboldt, 1996).

${ }^{26}$ WindsCHEID, Bernhard, Die Action des römischen Civilrechts, vom Standpunkte des heutigen Rechts (Düsseldorf, Julius Bideus, 1856). Este trabajo está traducido al español como La "actio" del derecho civil romano desde el punto de vista del derecho actual" en el volumen Polémica sobre la "actio" (Buenos Aires, EJEA, 1974). En palabras de NIEVA, Derecho, cit. (n. 25), p. 53: "Windscheid, interpretando libremente el Digesto, nos dijo que la "actio" romana, originariamente, no fue lo que la doctrina de su tiempo entendía por "acción” o "derecho de la acción" ("Klage”, "Klagerecht"), es decir, un medio de protección o defensa del derecho lesionado, que surgía de la lesión de ese derecho. Sino que la "actio" habría sido una expresión independiente con respecto al derecho, o incluso a la pretensión jurídica ("Rechtsanspruch"), pretensión que, por tanto, no debía confundirse con la actio, que sólo era una sombra del derecho sustantivo, o bien, la expresión (en el juicio) de ese derecho o pretensión. En el Derecho romano, por consiguiente, sólo se tenía un derecho cuando el pretor decía que se poseía una pretensión perseguible judicialmente, y esa expresión del pretor era la actio. De ese modo, esa actio habría estado a disposición del actor, en Derecho romano, incluso antes de la violación del derecho, aunque se ejerciera tras esa violación. Todo lo cual suponía rebatir la tesis principal de Savigny". Por su parte, Romero Seguel, Alejandro, Curso de derecho procesal civil (Santiago, Editorial Thomson Reuters, 2014), I, p. 11, sin embargo, valora la polémica Windscheid-Muther, a la que se debe "el nacimiento del derecho procesal como disciplina autónoma".

${ }^{27}$ MuTHER, Theodor, Zur Lehre von der römischen Actio, dem heutigen Klagrecht, der Litiscontestatio und der Singularsuccession in Obligationen. Eine Kritik des Winscheidschen Buchs, en Die Action des römischen Civilrechts, vom Standpunkte des heutigen Rechts (Erlangen, Andreas Deichert, 1857). En palabras de MarinONi y otros, cit. (n. 25), p. 155: "Muther sostuvo la idea de un derecho de acción contra el Estado 
los que sentaron las bases de este debate que continuó por décadas, con la idea de traspasarla al derecho procesal de su época (y de paso marcar la diferencia con la marea codificadora napoleónica), a pesar de lo inadecuada que resultó para parte de la doctrina, dadas las manifiestas diferencias entre la Roma clásica y el proceso jurisdiccional moderno ${ }^{28}$. Maturana hace una muy interesante mención a los orígenes históricos de la litispendencia, que precisamente se remonta como una excepción creada para la cognitio extra ordinem, sucesora de la litiscontestatio, esta última con un efecto preclusivo de mucho mayor alcance ${ }^{29}$, como se explica más adelante en este trabajo. Por lo mismo, es una empresa difícil buscar los puntos en común de la

en la persona de sus órganos jurisdiccionales, y también que la propia actio sería un derecho del actor para que el pretor le otorgara la "fórmula" que constituía, en su época, la tutela jurídica. Distinto a Winscheid, partió de la idea de que el sistema romano era diferente, no en un orden de derechos, sino de pretensiones que pueden ser "perseguidas judicialmente". Muther argumentó que el Derecho Romano era de derechos, diciendo que aquel que pedía la fórmula al pretor, también debía tener un derecho subjetivo, el cual, en su raciocinio, sería el propio fundamento del derecho a la fórmula”.

${ }^{28} \mathrm{El}$ mismo D'Ors, cit. (n. 21), p. 112, dice que "algunos procesalistas han querido entrometer a propósito de la actio romana el concepto moderno de "pretensión" (alem. "Anspruch"), lo que resulta perturbador para la inteligencia del derecho romano [...]. El edicto anuncia las acciones posibles, también propone las fórmulas civiles, y "tener derecho" quiere decir contar con una de esas acciones y esperar un resultado favorable".

${ }^{29}$ Maturana, cit. (n. 2), pp. 14-15: "el paso de la etapa in iure a la apud iudicem se efectuaba a través de la litiscontestatio, denominación que se deba en aquel entonces a los actos consistentes en la redacción y aprobación de la fórmula por el magistrado y la proposición formal que de ella hacía el demandante al demandado para su aceptación. Los efectos de la litiscontestatio eran los de un contrato novatorio, en virtud del cual la originaria relación material jurídica entre demandante y demandado quedaba sustituida por la mutua sumisión de las partes a lo que resolviera el juez. A partir de ese momento se encontraba pendiente el proceso. La acción era concebida como el derecho subjetivo deducido en juicio y se extinguía su ejercicio, esto es, desde el momento en que se configuraba la litiscontestatio [...]. En el procedimiento extraordinario, que se desarrollaba en una sola fase y ante un funcionario del Estado, la litiscontestatio ya no es fijada desde un punto de vista formal en un momento preciso al no existir un acto concreto que la denote, como la invocación de testigos en el procedimiento de la legis actiones o la entrega de la fórmula al demandado en el procedimiento formulario. Es por ello que en este procedimiento ya no se atribuye a la litiscontestatio el efecto que daba lugar a la oposición de la exceptio rei in iudicium deductae, otorgándose en su lugar al demandado solo una excepción de litispendencia de mucho menor energía y significación”. GUZMÁn, cit. (n. |14), p. 65, con cita a a Avsolomovich, Lührs y Noguera: "el contenido de la litiscontestatio actual, a semejanza de lo que sucedía en el proceso justinianeo, es que fija definitivamente las partes del proceso y establece en forma sustancial las peticiones que se someten a fallo del 
actual litispendencia con las teorías de la acción, que arrancan de la actio romana clásica. Así, Nieva ha dicho que la actio romana es una "reliquia histórica, que sólo tuvo sentido real en la época romana del proceso formulario. Y es que no tenía razón de ser recuperar una pieza de museo propia del proceso formulario, la actio, sin reinstaurar enteramente el modelo de dicho proceso formulario, o al menos un esquema similar"30.

Buena parte de la doctrina procesal contemporánea ha hecho notar la inutilidad de estas teorías frente a los desafíos del derecho procesal moderno, la que es consecuencia del tratamiento por completo diferente que recibe el concepto de "acción” en la actual ley y dogmática procesal, frente al concepto original del derecho romano. Por lo mismo, resulta un camino sumamente difícil de recorrer el vincular la litispendencia con la teoría de la acumulación de acciones, para la cual es necesario tener ciertos conceptos claros (si se puede) de las teorías de la acción. Teorías-porque son numerosas- que como he señalado, se apoyan en una idea romana del procedimiento formulario, es decir, de un número acotado de posibles acciones, que es diametralmente opuesta al derecho a la tutela judicial efectiva que propone la dogmática contemporánea. Nieva, frente a la inutilidad de las teorías de la acción, ha surgido una tendencia pragmática, precisamente para resolver los problemas de litispendencia del Tribunal de Justicia de las Comunidades Europeas, ha dicho que "hay que fijarse para decidir si dos procesos son iguales, es el punto central de la controversia, es decir, que se trate de la misma controversia sobre consecuencias jurídicas acerca de las mismas situaciones de hecho", por lo que aboga por "el completo olvido de las teorías [de la acción] y el examen directo del objeto de cada juicio, como nos recuerdan las doctrinas más modernas" ${ }^{31}$. Ya volveré sobre esto.

Como corolario de lo anterior, la teoría de la acumulación de acciones es también inidónea para tratar los problemas de la litispendencia, desde que las teorías de la acción en que se apoya adolece de los defectos que he reseñado someramente. Pero antes de tratar la acumulación de acciones, es necesario referirse al concurso de normas.

\section{El concurso de normas.}

Lo primero que hay que despejar es que el llamado concurso de normas no es lo mismo ni debe ser confundido con el concurso de acciones, si bien muchas veces se les asimila y se les trata como fenómenos afines o conexos ${ }^{32}$.

juez, de tal modo que, es posible a éste determinar aquellos hechos en que las partes están de acuerdo y aquéllos que aparecen controvertidos".

${ }^{30}$ Nieva, Derecho, cit. (n. 25), p. 53.

${ }^{31}$ Ibíd., p. 58.

${ }^{32}$ Alonso Traviesa, María Teresa, El problema de la concurrencia de responsa- 
Mientras el concurso de acciones es un tema exclusivamente procesal, el concurso de normas suele ser estudiado a propósito del derecho sustantivo, tanto civil como penal. El concurso de normas, que está detalladamente tratado a propósito de la parte general del derecho penal, se refiere a que unos mismos hechos pueden ser subsumidos en más de una descripción típica normativa ${ }^{33}$. En el derecho penal esto sucede al existir más de un tipo penal en que puede encasillarse la conducta del sujeto, lo que resulta atentatorio a la garantía del "non bis in idem", debiendo generar la ley y la doctrina distintas soluciones para evitar un doble castigo sobre la base de hechos idénticos.

En derecho civil el asunto es menos claro, y la doctrina lo ha tratado superficialmente ${ }^{34}$, porque en el derecho civil de daños por responsabilidad extracontractual no existe un conjunto de "tipos civiles" en que deban encasillarse las conductas ilícitas. Frente al sistema fragmentario, garantista y de última ratio del derecho penal, el sistema civil se erige como un continuo de ilicitudes bajo una fórmula tan genérica como es el "neminem laedere", que

bilidades (Santiago, LexisNexis, 2006), p. 334 y ss., trata precisamente el problema del concurso de acciones como los "problemas procesales" del también problema de la concurrencia de responsabilidades, haciendo alusión en la p. 349 al tema de la litispendencia.

${ }^{33}$ Mir, Santiago, Derecho penal. Parte general (Barcelona, Reppertor, 2012), p. 662, se refiere al "concurso de leyes", o sea, "cuando uno o varios hechos son incluidos en varios preceptos penales de los que sólo uno puede aplicarse, puesto que su estimación conjunta supondría un 'bis in idem'”. Entre nosotros, CurY, Enrique, en Derecho penal. Parte general (Santiago, Ediciones Universidad Católica de Chile, 2009), p. 663, se refiere al "concurso ideal de delitos" cuando "con un solo hecho se realizan las exigencias de dos o más tipos delictivos o de uno mismo varias veces".

${ }^{34}$ Con la excepción de BARros, Enrique, Tratado de responsabilidad extracontractual (Santiago, Editorial Jurídica de Chile, 2008), pp. 1055 ss. Dice este autor sobre el concurso de responsabilidades contractual y extracontractual: "los mismos hechos (o hechos que parcialmente se superponen) pueden satisfacer los supuestos de aplicación de distintas normas". Alessandri Rodríguez, Arturo, De la responsabilidad extra-contractual en el derecho civil chileno ([reimpresión] Santiago, Editorial Jurídica Ediar ConoSur, 1983), pp. 80 y 581, habla del cúmulo u opción de responsabilidades, frente al problema de que el actor pueda elegir el estatuto -contractual o extracontractual- que más le convenga. También habla del cúmulo en un sentido diverso, cuando la víctima tiene derecho a reparaciones adicionales a la que proviene del demandado, como cuando existen seguros o prestaciones de seguridad social. Corral, Hernán, Lecciones de responsabilidad extracontractual (Santiago, LegalPublishing, 2013), pp. 29-42 habla indistintamente del "cúmulo o concurso de responsabilidades”. También está la muy detallada monografía de Alonso Traviesa, cit. (n. 32). En España, entre otros, el trabajo de YzQuierdo Tolsada, Mariano, Sistema de responsabilidad civil extracontractual (Madrid, Editorial Dykinson, 2001), pp. 99-105. 
tiene como común denominador la sola ocurrencia de un daño susceptible de ser indemnizado ${ }^{35}$. Asimismo, en materia contractual la libertad de las personas para fijar a su arbitrio el contenido de las disposiciones y cláusulas, decanta también en infinitas posibilidades de contratos innominados. Y aun tratándose de contratos reglados específicamente por el Código Civil u otras leyes especiales, puede existir ciertamente una superposición de normas respecto de unos mismos hechos. Así, frente a un incumplimiento contractual, puede la parte perjudicada eventualmente reclamar la nulidad del contrato, su resolución, su cumplimiento forzado, la reivindicación de la cosa, etc. Por lo mismo, si en derecho penal el concurso de normas es un fenómeno que revela una legislación redundante y defectuosa, en el derecho civil este mismo fenómeno es consustancial a su estructura y principios: la reparación universal de todo daño causado ilícitamente, y la libertad contractual. Entonces, me parece erróneo hablar de la litispendencia como un "remedio" para una situación que no es de por sí patológica, sin perjuicio, como se expone más adelante, que corresponde a un escenario propicio para ciertos abusos.

\section{El concurso de acciones es consustancial al derecho a la tutela judicial} efectiva.

Por otra parte, distinguir el concurso de acciones del concurso de normas puede resultar una empresa no exenta de dificultades, dada la estrecha relación entre el derecho material tutelado y el contenido de la acción que se ejerce jurisdiccionalmente, que es precisamente uno de los nudos gordianos de la teoría de la acción. En general, se estima que hay concurso de acciones cuando sobre la base de idénticos hechos se pueden plantear peticiones diferentes, e incluso incompatibles, en sede jurisdiccional. Este "problema" del concurso de acciones, en realidad se adiciona al problema del concurso de normas: frente a idénticos hechos, el ciudadano puede elegir enmarcarlos en distintos estatutos normativos sustantivos, y asimismo, efectuar peticiones de distinta naturaleza frente a un tribunal ${ }^{36}$.

En un ejemplo quedará más claro: si una persona celebra un contrato de adhesión como consumidor, podrá elegir, frente al mismo incumpli-

${ }^{35}$ BARROS, cit. (n. 34), p. 215: "metafóricamente puede decirse que al comienzo de la responsabilidad civil está el daño. A diferencia de lo que ocurre en materia penal e infraccional, para el derecho civil sólo son relevantes las conductas culpables si de ellas se sigue un perjuicio para el demandante. En sede civil, la sola negligencia no es fuente de responsabilidad [...]. El objeto de la responsabilidad civil no es expresar un juicio de reproche, sino corregir el efecto adverso que el hecho del demandado haya causado a la víctima".

${ }^{36}$ Romero, Sophia, Concurso de normas y concurso de acciones en el derecho procesal civil chileno, en Ius et Praxis, 19 (Talca, 2013), 2, p. 226. 
miento, invocar la Ley de protección de los derechos de los consumidores, o el estatuto contractual civil (concurso de normas), y asimismo, podrá pedir la anulación, la resolución o el cumplimiento forzado del contrato (concurso de acciones $)^{37}$. Pero esta situación, de común ocurrencia en la práctica, no es patológica en sí misma. Es perfectamente lícito que una persona elija uno u otro estatuto sustantivo para apuntalar los hechos de su demanda, y haga las peticiones que estime convenientes ${ }^{38}$. Lo que no es admisible, repetimos, es la reiteración de demandas en distintos momentos del tiempo, para tratar de obtener un idéntico "bien de la vida" en cada uno de los procesos, sea en paralelo (de lo que se hace cargo la litispendencia y la acumulación de autos), sea una vez finalizado uno de ellos (lo que se soluciona con la cosa juzgada).

Esta teoría de la acumulación de acciones parte de una premisa errónea, tributaria de la teoría de la acción que ya analizamos, que es la supuesta existencia de un numerus clausus de acciones, de un catálogo acotado, como sí existía en el derecho romano. Pero esa no es la situación actual. En palabras de Alejandro Romero: "participamos de la doctrina que explica la naturaleza de la acción como un derecho subjetivo público, dirigido al órgano jurisdiccional para obtener la protección de los derechos e intereses legítimos" ${ }^{\prime 9}$. Hoy existen infinitas acciones, no sólo especificadas en numerosas leyes, sino acciones innominadas, que la doctrina suele agrupar bajo las categorías de acciones constitutivas, declarativas y de condena. Hay tantas acciones como derechos subjetivos e intereses legítimos existen, y no existe límite alguno para su interposición ni reconocimiento. La tutela judicial efectiva, como derecho objetivo y constitucionalmente garantizado, supone no limitar al actor en el catálogo de acciones que

${ }^{37}$ Las hipótesis parecen bastante más complejas que lo que alguna vez avistó Liebman, Tulio Enrico, Eficacia y autoridad de la sentencia y otros estudios sobre la cosa juzgada (Buenos Aires, Editorial Ediar, 1946), p. 248. Este autor decía que "a todo concurso de derechos corresponderá un concurso de acciones", lo que es verdad, pero sin dejar de lado que cada norma sustantiva invocada a su vez puede dar origen a varias acciones. O lo que es lo mismo: aun sin concurso de normas, puede existir concurso de acciones.

${ }^{38}$ Romero, cit. (n. 36), p. 214, señala respecto del concurso de normas que "en la realidad, la existencia de estas normas no supone en muchos casos una respuesta intencionada de nuestro legislador, sino más bien un defecto de técnica legislativa causado, entre otras razones, por presiones sociales que persiguen reivindicar mecanismos de tutela a los ciudadanos, en consideración a situaciones especiales o derechamente a un descuido derivado de la informalidad práctica que se produce dentro del proceso legislativo".

${ }^{39}$ Romero Seguel, Curso, cit. (n. 27), p. 8. 
desee ejercer ${ }^{40}$. Por lo tanto, puede decirse que la idea misma -o el problema- de la acumulación de acciones es consustancial a la tutela judicial efectiva. O lo que es lo mismo: no puede haber tutela judicial efectiva si se limitan las acciones que el ciudadano puede ejercer. En este sentido, "la genética jurídica del derecho fundamental de la acción no es la de la actio romana, sino de la gesta libertaria del constitucionalismo que se remonta en su primer momento a la Inglaterra de 1215 ("Magna carta libertatum"). El contenido del derecho de acción es libertario y social”¹.

${ }^{40}$ Por lo mismo, las limitaciones introducidas en el derecho comparado no han estado exentas de polémica. En la Ley de Enjuiciamiento Civil española del año 2000 se introdujo el conocido artículo 400, cuyo inciso primero dispone lo siguiente: "Cuando lo que se pida en la demanda pueda fundarse en diferentes hechos o en distintos fundamentos o títulos jurídicos, habrán de aducirse en ella cuantos resulten conocidos o puedan invocarse al tiempo de interponerla, sin que sea admisible reservar su alegación para un proceso ulterior", aludiendo el inciso segundo al efecto de cosa juzgada y litispendencia. Esta norma tiene cierta semblanza con la institución romana de la litiscontestatio reseñada por LieBMAN, cit. (n. 37), p. 244, que extinguía todas las posibles y eventuales acciones concurrentes entre las partes del juicio, si sólo se ejercía una de ellas. Respecto de este artículo 400, SolÉ, Jaume, en Convergencias y divergencias entre los procesos civily penal. Perspectiva del abogado civilista, en ARMENTA (coordinador), La convergencia entre el proceso civil y penal ¿Una dirección adecuada?, (Madrid, Marcial Pons, 2013), pp. 129-132, ha dicho que "supone una afectación al principio o garantía de libertad de acción que consagra el artículo $24 \mathrm{CE}$. Este precepto no restringe el acceso a los Tribunales en cualquier momento que sea necesario $y$ en cuantos juicios sean pertinentes [...]. El juicio civil se inspira en un criterio de libertad de elección de los hechos que el ciudadano quiere que los tribunales enjuicien. Ninguna norma de nuestro ordenamiento jurídico limita el número de veces que se puede acudir a los tribunales; para eso ya están dos instituciones consagradas como son la cosa juzgada y la litispendencia [...]. La norma supone también un atentado contra el ejercicio de la jurisdicción, pues los fundamentos de derecho son fungibles, de acuerdo con la máxima del iura novit curiae". En contra de esta opinión encontramos entre nosotros a HunTER, Iván, en La aplicación judicial del derecho en el proceso civil. Doctrina, jurisprudencia y derecho comparado (Santiago, Thomson Reuters, 2015), p. 152, quien señala respecto de lo que algunos autores han llamado la "cosa juzgada virtual" lo siguiente: "la cosa juzgada produce un importante efecto preclusivo sobre la argumentación jurídica, en el sentido que la fundamentación de una pretensión que no se hizo valer en un pleito no puede alegarse en uno posterior [...]. Por eso es natural entender que la cosa juzgada despliega sus efectos tanto sobre los argumentos jurídicos efectivamente alegados como sobre aquellos en que sin ser alegados pudieron serlo". Acerca de la cosa juzgada y litispendencia "virtual" que abarca lo "deducible" en el proceso, y no sólo lo deducido, ver también la obra de DE LA Oliva Santos, Andrés, Objeto del proceso y cosa juzgada en el proceso civil (Navarra, Thomson - Civitas, 2005), pp. 78-85.

${ }^{41}$ GonZÁlez Álvarez, Roberto, El principio fundamental de acción. Nuevo paradigma de la ciencia procesal, en Ars Boni et Aequi, 7 (Santiago, 2011) 2, p. 20: 
O como señala Bordalí: "la actividad procesal se desarrolla no porque existan derechos materiales previos, sino porque precisamente existe un derecho de acción, constitucionalmente reconocido, de contenido material y anterior al proceso, que da inicio al proceso desarrollado ante la jurisdicción”². En el trabajo que he citado de los profesores Marinoni, Pérez Ragone y Núnez Ojeda el problema de las teorías de la acción se trata precisamente en íntima relación a cómo se concibe actualmente: "el derecho de acción como derecho de acceso a la justicia" ${ }^{43}$, postura que no sólo es coherente con las ideas liberales que inspiraron el Código chileno en su momento -como una forma de libertad negativa del ciudadano frente al juez estatal- sino sobre todo hoy como el ejercicio ya no de la acción, sino del "derecho de acción" como una libertad positiva que permita asegurar jurisdiccionalmente frente al propio Estado los derechos consagrados en la carta fundamental y las leyes. La mejor muestra de esto es la norma del artículo 17 CPC., que permite ejercer acciones simultáneas siempre que sean compatibles; y aun intentar acciones incompatibles, siempre que se hagan en forma subsidiaria una de la otra.

Así, el juez civil carece de herramientas para desechar prima facie una demanda que contiene una acción inexistente o mal planteada ${ }^{44}$. Ningún tribunal civil inadmitirá una demanda porque la "acción es inexistente". En la práctica forense chilena al menos, la excepción de "improcedencia de la acción deducida" es una excepción perentoria de fondo, que el juez recién resolverá al pronunciarse sobre todas las alegaciones del proceso, en la sentencia definitiva. Lo anterior no significa avalar, ni mucho menos, la confusión que muchas veces debe superar el litigante al momento de

"la acción como principio fundamental tiene un contenido fundamental: derechos de postular, alegar, probar, confirmar, impugnar, a reconocer hechos, desistirse de pretensiones, de actos o del proceso. Los derechos no son sus garantías, no existen derechos-garantías".

${ }^{42}$ Bordalí, Andrés, El derecho fundamental de acción: un intento de configuración en el orden constitucional chileno, en Revista de Derecho y Jurisprudencia, 97 (Santiago, 2000), 3, p. 730. Dice: "atribuir la acción a un derecho material previo, corresponde a una concepción monista de la acción, que supone recién el paso siguiente de la visión romanista de la misma -se tenía un derecho subjetivo porque se reconocía previamente una acción-, es decir, propio de la concepción también monista del siglo XIX, expresada fundamentalmente por Savigny, que atribuye la acción procesal a quien es titular de un derecho subjetivo". Para este autor, la tutela judicial efectiva sería una garantía reconocida en el artículo $19, \mathrm{~N}^{\circ} 3$ inciso $1^{\circ} \mathrm{CPol}$.: "la igual protección de la ley en el ejercicio de sus derechos".

${ }^{43}$ MarinONi, cit. (n. 25), pp. 149-210.

${ }^{44} \mathrm{Al}$ respecto, el interesante trabajo de HunTER, Iván, El poder del juez para rechazar "in limine" la demanda por manifiesta falta de fundamento, en Ius et Praxis, 15 (Talca, 2009) 2. 
plantear su demanda, debido a la existencia de estatutos legales superpuestos, producto de la hiperinflación legislativa. Pero en general, la tendencia jurisprudencial, muy acorde a los principios que inspiran el proceso (dispositivo) y la Constitución Política (derecho de propiedad), es la de reconocer una amplia libertad al litigante para intentar toda clase de acciones, en la medida en que exista al menos un interés legítimo, y no rechazar demandas por existir una norma sustantiva o procesal mal invocada, o por no existir siquiera una que invocar. Esto se ve muy claro en los fallos recientes de la Corte Suprema, que han permitido demandar en forma directa una indemnización de perjuicios sin ser necesario deducir una demanda de resolución o de cumplimiento forzado de contratos ${ }^{45}$.

La libertad al accionar, por otra parte, es una consecuencia de que el contenido mismo de la acción no lo determina al litigante en forma total. Si tomamos los tres elementos de la acción -los hechos, el derecho y la petición concreta-, tenemos que hoy la tendencia doctrinaria y jurisprudencial arraigada es dotar de un contenido bastante concreto y amplio a la regla "iura novit curia", el derecho del tribunal de fijar libremente las normas aplicables a los hechos ventilados en el proceso por las partes ${ }^{46}$. En

${ }^{45} \mathrm{La}$ Corte Suprema en un fallo de 31 de octubre de 2012, en causa rol $\mathrm{N}^{\circ}$ 3325-2012 resolvió: " 9 ': Una vez establecido que efectivamente ha existido un incumplimiento del contrato, corresponde determinar si la actora ha podido ejercer la acción indemnizatoria, como lo ha hecho, prescindiendo de lo que disponen los artículos 1489 y 1826 del Código Civil, que parecen indicar que tal acción no es autónoma, sino que debe siempre ir acompañada sea de la petición de resolución contractual, o bien, de la exigencia de cumplimiento del contrato. Como ya lo ha resuelto esta Corte en otras oportunidades, y siguiendo una moderna tendencia doctrinal (Rol 3.341-012), se estima que, en este caso, la demandante ha podido plantear su demanda de responsabilidad civil contractual, sin asociarla a la resolución del contrato, pues, la entrega material de los rodillos está cumplida y parte de ellos fueron cortados".

${ }^{46}$ Hunter, La aplicación, cit. (n. 40) p. 108, lo mismo que De la Oliva Santos, cit. (n. 40), p. 69, distinguen entre "el fundamento de lo pedido que coincide con la causa de pedir y que viene dado por un conjunto de hechos de los cuales se desprende un beneficio jurídico perseguido, y la fundamentación que se trataría de un ejercicio racional destinado a dar razones para estimar o rechazar la pretensión". Respecto de las fundamentaciones, según recoge cierta jurisprudencia chilena, el tribunal sería soberano para apreciarlas o desecharlas, posición que es criticada por el primero de estos autores, quien propone cierta libertad del juez para adjudicar los hechos a normas no propuestas por las partes, en la medida en que se haya debatido entre las partes durante el proceso la nueva calificación jurídica. Este autor, citando a ORMAZÁBAL, Guillermo, en Iura novit curia. La vinculación del juez a la calificación jurídica de la demanda (Madrid, Santiago, Editorial Marcial Pons, 2007), pp. 89 y 90 señala, con toda razón que "quien acude a los tribunales pretende la declaración a su favor de un cierto efecto jurídico, el reconocimiento de una determinada tutela". Asimismo, y esto en palabras del propio HunTER, La aplicación, cit. (n. 40). 79, "no es razona- 
este sentido, como acota Sophia Romero, "en la actualidad, desaparecido este efecto consumativo y en donde el concepto relevante es el de derechos subjetivos y no ya el de acción, la forma de limitar la posibilidad de procesos con un mismo objeto en la mayoría de los casos no viene dada por el legislador. Es por ello que estimamos que efectuando un análisis de los hechos jurídicamente relevantes y de las peticiones efectuadas se puede acotar la posibilidad de iniciar un nuevo proceso con objeto idéntico o limitar sus efectos por identidad parcial" ${ }^{77}$. Como se dirá a propósito de los casos de conexidad y prejudicialidad, lo relevante en la litispendencia está lejos de ser la coincidencia en el derecho invocado, o los hechos expuestos en la demanda, y menos la petición invocada. Pero en este punto disiento con esta autora: lo relevante es el "bien de la vida" perseguido en cada acción que se reitera, más allá de las formas procesales, los hechos invocados o el derecho que se pide aplicar. Y, por supuesto, el concepto de abuso procesal y de buena fe procesal son claves para apreciar la litispendencia, como se expone en el apartado siguiente.

Quizás la solución a estos temas va en la línea de lo que Jaime Guasp ${ }^{48}$ elaboró hace ya treinta años, al diferenciar, por un lado, entre el derecho a la acción, anterior al proceso y que se ejercer respecto del Estado (hoy diríamos: jurisdiccionalmente tutelado), y por otro, la pretensión que se concreta a través de la acción, que para Guasp no es sino el objeto mismo del proceso. La pretensión es el contenido de la acción, y es en ella donde debiera buscarse entonces las coincidencias entre uno y otro proceso, no en la acción ejercida, que finalmente no es más que el interés genérico,

ble creer que el justiciable pueda buscar tutela a sus derechos en base a una precisa calificación que considere inalterable cuando se manifieste inidónea para producir el efecto jurídico deseado [...] parece ser que el principio dispositivo se manifiesta en la petición, esto es, en el concreto bien de la vida que se solicita”.

${ }^{47}$ Romero, cit. (n. 36), p. 211.

${ }^{48}$ GuASP, Jaime, La pretensión procesal (Madrid, Civitas, 1985), p 361: "la acción, la idea soberana del proceso, resultaba demasiado elevada para encadenar las explicaciones concretas de muchas teorías como la de la litispendencia, la de la congruencia, la de la cosa juzgada, y así sucesivamente". En el mismo sentido, cita CoRDÓN MoRENO, Faustino, La excepción de litispendencia. Comentario a la STS de 25 de febrero de 1992 (Repertorio de Jurisprudencia Aranzadi 1552, en Revista Jurídica de Navarra, 15 (1993), p. 59, un fallo del Tribunal Supremo español de 1989: "respecto a la causa petendi debe repararse solamente en la identidad fundamental, atendiendo más que al nombre que se dé a las acciones, a la finalidad que con ellas se persigue, de modo que concurrirá si existe una contradicción manifiesta entre lo que pende de resolución y lo que se pretende con la nueva demanda, lo que reconduce la cuestión al concepto de pretensión y sus elementos identificadores". 
muchas veces anclado en un derecho subjetivo, que toda persona tiene derecho a que se tutele por el Poder Judicial.

En suma, la litispendencia no es un remedio para superar la concurrencia o cúmulo de acciones, desde que el derecho constitucionalmente garantizado a la tutela judicial efectiva impide hablar de una verdadera limitación al ejercicio de acciones jurisdiccionales, y por el contrario, fomenta su ejercicio en la medida que el justiciable exhiba siquiera un interés legítimo (ya ni siquiera un derecho subjetivo) que merezca ser amparado por una sentencia jurisdiccional.

\section{EL FIN DE LA LITISPENDENCIA: EVITAR ABUSOS PROCESALES Y DESINCENTIVAR LA LITIGACIÓN DE MALA FE}

Posiblemente el asunto más importante referido a la litispendencia, y del que menos se trata en manuales y monografías, es cuál es el objeto de esta institución procesal. En buenas cuentas: para qué sirve la litispendencia. Ya hemos visto que ese objeto no consiste en solucionar el supuesto problema del cúmulo de acciones o de normas. Un análisis teleológico se hace imprescindible, desde que la litispendencia está emparentada con otros dos institutos que parecen cumplir idénticos fines: la acumulación de autos y la cosa juzgada. Respecto de estas tres instituciones, puede decirse que resguardan exactamente lo mismo: evitar duplicidad de juicios (" $n o n$ bis in idem"), evitar juicios inútiles, favorecer la unidad y continencia del proceso, la economía procesal, y sobre todo, impedir que se generen sentencias contradictorias. Para despejar el insustituible valor de la litispendencia frente a sus dos "hermanas", es necesario despejar algunos temas.

Respecto de la cosa juzgada, salta a la vista inmediatamente que -al menos en la ley procesal civil chilena vigente- se exige la concurrencia de una estricta triple identidad legal, lo que no ocurre respecto de la litispendencia. Esta triple identidad, como acota Nieva, partió en el Digesto justinianeo como una simple "guía" para el juzgador, pero devino en un asfixiante dogma que fue adoptado por buena parte de las leyes procesales de tradición europea continental, incluida la chilena ${ }^{49}$. Sin embargo, existe cierto consenso en la doctrina acerca de que se trata de un profundo error, al punto que el Proyecto de Código Procesal Civil chileno la eliminó como requisito de la cosa juzgada. Como acota Nieva, serán muy contados los casos en que se interponga exactamente la misma demanda dos veces, siendo muchos más aquellos en que un litigante vencido e insatisfecho

${ }^{49}$ Nieva, Jordi, La cosa juzgada (Barcelona, Atelier Derecho, 2006), pp. 38-45. Según este autor, habría sido von Savigny el responsable de la confusión. 
intente revivir el pleito cambiando ciertos aspectos no esenciales del proceso anterior, plasmados en una nueva demanda. La simplicidad con que fue concebida originalmente la litispendencia, ajena a esta triple identidad legal, es indicativa de un fin mucho más amplio que la simple protección del "non bis in idem" del demandado. Por lo demás, como acota Jaime Vegas, "la incoación de un segundo proceso cuando se encuentra pendiente otro sobre idéntica cuestión no supone por sí sola una amenaza cierta a la prohibición del "bis in idem", ya que el primer proceso podría finalizar sin decisión de fondo, y en tal caso ningún obstáculo existiría" ${ }^{\circ 0}$. Como acota el mismo autor, la inutilidad del segundo proceso es también incierta, lo que sólo ocurrirá si el primer juicio termina con una decisión sobre el fondo. Por estas razones no tiene sentido pensar que cosa juzgada y litispendencia protegen exactamente lo mismo, pero en distintos momentos, como buena parte de la doctrina afirma.

Respecto de la acumulación de autos, el tratamiento en la ley chilena de esta institución puede llevar a confusión, ya que pareciera que ambas abarcan exactamente los mismos supuestos. El artículo 92 CPC dispone que "la acumulación de autos tendrá lugar siempre que se tramiten separadamente dos o más procesos que deban constituir un solo juicio y terminar por una sola sentencia, para mantener la continencia, o unidad de la causa". A continuación, la norma da una enumeración, a juicio de Carlos Alberto Stoehrel, "no taxativa" de casos que serían "meros ejemplos" 51. El número 1 de este artículo señala como ejemplo "cuando la acción o acciones entabladas en un juicio sean iguales a las que se haya deducido en otro, o cuando unas y otras emanen directa e inmediatamente de unos mismos hechos", y el número 3 dice "en general, siempre que la sentencia

${ }^{50}$ Vegas Torres, Jaime, La eficacia excluyente de la litispendencia, en Revista Electrónica del Departamento de Derecho de la Universidad de La Rioja (Logroño, 2002), p. 171. En contra de esta opinión se manifestaba, por ejemplo, Maturana, cit. (n. 2), p. 485, quien asimilaba los fines de la cosa juzgada, litispendencia y acumulación de autos, señalando que "podemos concluir que la litispendencia y la acumulación de autos, mientras los procesos se encuentran en tramitación, y la cosa juzgada, cuando uno de los procesos se encuentra afinado, son los medios legales de que se vale el legislador para poner obstáculos a las modificaciones o contradicciones que pueden producirse entre sentencias, atentando contra la certeza, que de ellas emana, acerca de lo cual es el contenido del derecho para una situación concreta y particular". Esta identidad entre litispendencia y cosa juzgada, ha sido criticada por DE LA OLIVA SANTOS, cit. (n. 40), p. 12, señalando que no es lo mismo la res iudicanda (que se identifica con el objeto del proceso) que la res iudicata (identificada con la cosa juzgada).

${ }^{51}$ Stoenrel, Carlos Alberto, De las disposiciones comunes a todo procedimiento y de los incidentes. (6 $6^{\mathrm{a}}$ edición revisada y actualizada por Davor Harasic Yaksic, Santiago, Editorial Jurídica de Chile, 2011), p. 156. 
que haya de pronunciarse en un juicio deba producir la excepción de cosa juzgada en otro". Ambos ejemplos dan una clara idea de superposición respecto de los supuestos que tradicionalmente se consideran propios de la litispendencia. Esta superposición es notada por Stoehrel, quien acota-con razón-que "ambas instituciones no son incompatibles" 52 . Efectivamente no son incompatibles, pero sus efectos son bien diversos. Por un lado, existe cierto consenso en la doctrina y jurisprudencia chilena acerca del efecto de la litispendencia en cuanto suspender el segundo proceso mientras no se resuelva el primero (lo que de facto en muchos casos implica poner fin al segundo proceso). Y por otro lado, la acumulación conduce a que ambos procesos se tramiten conjuntamente y concluyan en una sola sentencia.

Recapitulando: i) la litispendencia no cumple necesariamente con proteger la garantía del non bis in idem del demandado ni previene juicios inútiles, objetivos que sí custodia la cosa juzgada; y ii) la acumulación de autos y la litispendencia actúan sobre la base del mismo supuesto -identidad de acciones- aunque producen efectos bien diversos. Esto obliga a buscar un fin diferente que explique la existencia de esta institución, y sobre todo, que justifique el drástico efecto que tiene frente a la nueva demanda del actor, si se le compara con el que produce la simple acumulación. En este punto es necesario detenerse en la experiencia que cualquier litigante y operador jurídico tiene respecto de la litispendencia, que generalmente se apoya en la denuncia del demandado frente a un abuso procesal del actor, quien ha intentado dos o más acciones con el mismo objeto. La litispendencia es el arma procesal que protege al demandado de una sucesión de acciones iguales o similares. Si bien el actor goza del derecho constitucionalmente garantizado a una tutela judicial efectiva de sus intereses, es claro que ese derecho reconoce como límite un ejercicio abusivo de éste, en desmedro de los derechos del demandado. Por lo mismo, no puede concebirse la litispendencia en forma aséptica, desligada de la realidad procesal, y sobre todo, de las motivaciones de las partes en el proceso y sus deberes de buena fe.

Respecto de la cosa juzgada, Nieva cuestionaba, con razón, que la triple identidad legal fuera efectivamente un requisito, desde que parecía inverosímil que una parte interpusiera exactamente la misma demanda una vez zanjado el asunto por sentencia firme, siendo en cambio más plausible que se intentara una demanda similar, para conjurar esa firmeza. Sin embargo, tratándose de la litispendencia, es perfectamente posible pensar en el caso de un actor que intente exactamente la misma acción estando en trámite una primitiva demanda, con idénticos caracteres. Las razones

\footnotetext{
${ }^{52}$ Ibíd., p. 159.
} 
para este tipo de comportamiento no son difíciles de adivinar, y la práctica judicial muestra con demasiada frecuencia casos en que el actor trata de revivir "desde cero" procesos mal tramitados, o en que el demandado interpuso excepciones que tienen posibilidad de éxito, sin esperar la conclusión de éstos ${ }^{53}$. Jaime Vegas atribuye así un fin de "economía procesal y buen orden y funcionamiento de la Administración de justicia", y como "factor disuasorio de la incoación de ulteriores procesos sobre asuntos ya sometidos a la consideración de los tribunales" $"$. Puede decirse que la litispendencia es el reconocimiento procesal del principio civil del "venire contra factum proprium non valet" 55 , es decir, la teoría de los actos propios. Se penaliza así al litigante que habiendo abierto un proceso en el pasado, vuelve a iniciar uno idéntico, sin haber concluido el primero. El segundo proceso es visto, entonces, como un acto que contradice la presentación de la primera demanda ya intentada, ya que el sistema no permite la reiteración de juicios, por razones obvias de seguridad jurídica y economía procesal. También puede ser visto como una manifestación del principio del "nemo auditor propriam turpitudem allegans" ("nadie puede ser oído cuando alega su propia ilicitud"), en los casos en que el segundo proceso tenga un fin evidente o declarado de sanear los problemas procesales u omisiones sustantivas del primer juicio. Alejandro Romero Seguel cita un fallo de la Corte Suprema, en que "se calificó de actuación contraria a la buena fe la iniciación separada, por la misma demandante, de pretensiones contradictorias. El actor, en un primer proceso, pidió la rescisión de una compraventa por lesión enorme, y luego inició otro, impetrando la nulidad absoluta del mismo contrato, fundado en una simulación por falta de consentimiento" 56 . Goldschmidt acuñó el concepto de la "eventualidad de los actos procesales", vinculado a la preclusión, que la litispendencia podría prevenir (la posibilidad de la parte de reservarse ciertas alegaciones para el evento que las anteriores fracasen $)^{57}$.

Esta mala fe al litigar -no esperar la conclusión de un proceso para

${ }^{53}$ VEGAS, cit. (n. 50), p. 173.

${ }^{54}$ Ibíd., p. 172.

${ }^{55}$ EKDAHL, María Fernanda, La doctrina de los actos propios. El deber jurídico de no contrariar conductas propias pasadas (Santiago, Editorial Jurídica de Chile, 1989), pp. 103 ss.; CARRETTA, Francesco, La coherencia en el proceso civil. Imperativo conductual $y$ decisional desde la buena fe (casos y jurisprudencia) (Santiago, Thomson Reuters, 2013), pp. 79-98.

${ }^{56}$ Romero Seguel, Alejandro, El principio de la buena fe procesal y su desarrollo en la jurisprudencia, a la luz de la doctrina de los actos propios, en Revista Chilena de Derecho, 30 (Santiago, 2003), pp. 168-172.

${ }^{57}$ Goldschmidt, James, Derecho procesal civil (Barcelona, Editorial Labor, 1936), p. 85. 
iniciar uno nuevo- se ve favorecida por una serie de circunstancias, parte de las cuales ya he mencionado. En primer lugar, como dije, la existencia de infinitas acciones posibles para tutelar también infinitos bienes jurídicos creados a partir de la libertad contractual o desde el sistema de "ilícitos continuos" de la responsabilidad civil extracontractual. El problema no es la coexistencia de todos estos derechos, normas y acciones. El problema es su ejercicio abusivo. Por lo demás, como acota Vegas, la tutela judicial efectiva se encontrará de todas formas resguardada por el primer proceso, que siempre subsistirá, por lo que en caso alguno puede hablarse de denegación de justicia. En segundo lugar, en Chile no existe un sistema de tasas judiciales que desincentive la iniciación de procesos frívolos o repetidos ${ }^{58}$, y asimismo, el juez civil tiene muy escasas facultades de rechazar in limine litis demandas nuevas ${ }^{59}$, no existiendo mayor examen de admisibilidad que el cumplimiento formal de los requisitos del artículo 254 CPC. ${ }^{60}$. Tampoco el sistema automático de distribución de causas entre tribunales civiles en lugares que son asiento de Cortes de Apelaciones ha probado ser efectivo, sistema que teóricamente provocaría que las demandas idénticas siempre se radicaran ante el mismo juzgado.

Este fin de preservar la buena fe en el proceso ha sido expresado en forma muy categórica por Vegas, criterio al que adhiero plenamente: "no cabe imaginar ningún supuesto en el que la presentación de una segunda demanda relativa a un asunto ya pendiente en otro proceso pueda responder a una finalidad legítima digna de ser tutelada por el ordenamiento jurídico. Y sí son imaginables, por el contrario, multitud de finalidades ilegítimas que justiciables poco escrupulosos podrían pretender lograr mediante la multiplicación de demandas sobre la misma cuestión" ${ }^{61}$. Hay que tener presente que nuestra ley procesal permite intentar varias acciones en una misma demanda, compatibles o no (artículo 17 CPC.), e incluso modificar la demanda antes de su contestación. También se permite hacer adiciones en la réplica. Por lo mismo, si un actor no aprovecha esas instancias para plantear una segunda pretensión y prefiere, en cambio, iniciar un segundo proceso aparte, parece razonable aplicar la litispendencia como sanción a su desidia y posible mala fe procesal.

Dogmáticamente está asentado que el proceso no es un área ajena

${ }^{58}$ Equipo Consultor Facultad de Economía y Empresa Universidad Diego Portales, Tasas judiciales en la experiencia comparada (Santiago, 2012).

${ }^{59}$ Redenti, Enrico, Derecho procesal civil (Buenos Aires, Ediciones Jurídicas Europa-América, 1957), p. 361.

${ }^{60}$ Alonso Traviesa, cit. (n. 32), p. 353, asigna sólo un "valor relativo" esta norma procesal.

${ }^{61}$ Vegas, cit. (n. 50), p. 174. 
al cumplimiento de los deberes de buena fe. Si bien nuestra legislación positiva no contempla un reconocimiento de dicho deber ${ }^{62}$, existe un consenso doctrinal y jurisprudencial al respecto. No es posible abogar por un principio dispositivo a ultranza, en que el juez no puede intervenir si detecta, como en el caso que nos ocupa, duplicidad de procedimientos. Como afirma Francesco Carretta: "el proceso ya no se confunde con su objeto, que son los intereses particulares que canaliza. Bajo una concepción constitucional y pública del proceso civil, es un instrumento de justicia y una garantía para la vigencia de los derechos de las partes" 63 . Por otra parte, Pía Tavolari, a propósito del abuso en el proceso, se hace cargo precisamente de los casos de "abuso contextual o por reiteración", señalando que "el abuso de las vías procesales puede consumarse, a veces, a raíz de repeticiones de conductas que aisladamente no repugnan sino que se ajustan al ordenamiento jurídico" 64 .

Todas estas consideraciones llevan a concluir que, dada la drástica consecuencia de la litispendencia frente a los mismos supuestos en que procede la acumulación de autos (artículo $92 \mathrm{~N}^{\circ} 1$ y 3 ), el juez deberá inclinarse por acoger la litispendencia en aquellos casos en que observe positivamente un comportamiento abusivo, irregular y contrario a la buena fe por parte del actor que ha incoado dos o más procesos idénticos. En aquellos casos,

${ }^{62}$ En otros ordenamientos sí existe un reconocimiento expreso. Así, en el artículo 247 de la Ley de Enjuiciamiento Civil española se establece que "los intervinientes en todo tipo de procesos deberán ajustarse en sus actuaciones a la regla de la buena fe". En el entorno latinoamericano, llama la atención el Código Procesal Civil de Perú que en su artículo IV del Título preliminar dispone que "las partes, sus representantes, sus abogados y, en general, todos los partícipes en el proceso, adecuan su conducta a los deberes de veracidad, probidad, lealtad y buena fe. El juez tiene el deber de impedir y sancionar cualquier conducta ilícita o dilatoria", como asimismo el artículo 282, que dispone lo siguiente: "Presunción y conducta procesal de las partes. El juez puede extraer conclusiones en contra de los intereses de las partes atendiendo a la conducta que éstas asumen en el proceso, particularmente cuando se manifiesta notoriamente la falta de cooperación para lograr la finalidad de los medios probatorios, o con otras actitudes de obstrucción. Las conclusiones del juez estarán debidamente fundamentadas". MONROY GÁlvEZ, Juan - Monroy Palacios, Juan José, Las relaciones entre jueces, partes y abogados en el proceso civil peruano, en De La Oliva y otros (coordinadores), Proceso civil. Hacia una nueva justicia civil (Santiago, Editorial Jurídica de Chile, 2007), p. 642, han dicho sobre esta última norma que es "probablemente la mejor demostración de la singular importancia que el legislador nacional le ha dado a la relación juez/parte en el proceso", al regularse "como un auxilio de prueba la apreciación judicial de la conducta procesal de la parte".

${ }^{63}$ Carretta, cit. (n. 55), pp. 190-191.

${ }^{64}$ Tavolari, Pía, El abuso en el proceso ("Prólogo" de Manuel Ortells Ramos, Ediciones Congreso, Santiago, 2004), p. 124. 
en cambio, en que aparece un segundo pleito con intenciones legítimas, en que genuinamente existe un asunto no cubierto por el primer litigio, el juez debiera de oficio o a petición de parte acumular los procesos al más antiguo, como dispone la ley procesal chilena, en orden a no perjudicar al actor del segundo proceso. El comportamiento procesal del actor fuera del proceso (en otro proceso) es un elemento muy relevante al momento de apreciar la litispendencia. Siendo una institución propia de la ciencia procesal, la litispendencia no puede solamente fijarse en los elementos de identidad o conexidad que se extraen de la demanda (hechos, derecho invocado, pretensión). Lo que se expone en la demanda es el contenido del proceso, pero no es el proceso mismo. Lo que permitirá apreciar la identidad o conexión de dos procesos será la mala fe del actor, el abuso procesal cometido, la reiteración ilícita de demandadas.

La doctrina española ha llegado a decir que la litispendencia puede ser apreciada de oficio por el tribunal, y por lo mismo, no mira solo al interés particular de los litigantes, cuando existe "un uso abusivo del derecho a la jurisdicción manifestado en la reproducción de pretensiones idénticas ante los diferentes órganos judiciales o, sucesivamente, ante el mismo órgano" 65 .

Como se señaló al comienzo de este trabajo, el Proyecto de Código Procesal Civil en actual tramitación da una expresa preferencia a la excepción de litispendencia, frente a la acumulación de autos, "cuando la sentencia que haya de pronunciarse en un procedimiento pueda producir efecto de cosa juzgada en otro u otros procesos" (artículo 56), hipótesis que configura simultáneamente -igual que hoy- uno de los presupuestos de la litispendencia y de la acumulación de autos.

\section{LA LITISPENDENCIA POR CONEXIDAD Y PREJUDICIALIDAD}

El tercer tema a tratar en este trabajo, siempre girando en torno a la litispendencia, es si esta institución procesal abarca también los casos de conexidad de procesos y de prejudicialidad de un proceso frente a otro u otros. He hecho una breve referencia al comienzo de este trabajo acerca de i) la ausencia de contenido normativo positivo de la litispendencia; y ii) que ese contenido ha sido llenado por la doctrina y la jurisprudencia, que han dicho que la litispendencia debe entenderse solamente como una cosa juzgada anticipada, y por lo mismo, estrictamente apegada a la triple identidad legal entre los procesos. ¿Es esta una solución correcta y razonada? A mi entender, no. Como fundamentaré en este apartado, no existe razón valedera alguna -más allá del apego a cierta tradición- para circunscribir la

${ }^{65}$ Cordón Moreno, cit. (n. 48), p. 62. 
litispendencia al requisito de la triple identidad; por el contrario, existen varias y buenas razones, que ya se han ido esbozando en este trabajo, para hacer extensivos sus efectos a los casos de procesos conexos -no acciones conexas- $y$ de procesos prejudiciales a otros. Lo primero será entonces dar un concepto de procesos conexos y de prejudicialidad.

\section{Procesos conexos.}

En este punto quiero apartarme de la discusión respecto de acciones conexas, y he empleado ex profeso el concepto más amplio de "procesos conexos". La doctrina ha detectado desde hace ya bastante tiempo, que el factor de conexión entre un proceso y otro no puede ser la norma legal invocada. Como hemos dicho, la adjudicación se estima actualmente una prerrogativa exclusiva del juez del fondo, quien no necesariamente estará vinculado frente al marco legal expuesto en la demanda, si bien la exposición del derecho aplicable sigue siendo un requisito de la misma, según dispone el actual artículo 254 CPC. También se ha dicho que la pretensión no sería necesariamente un factor vinculante. En estos dos extremos estoy plenamente de acuerdo. Sin embargo, la doctrina estima que los hechos expuestos sí son un factor vinculante entre un proceso y otro, y que sería el factor distintivo para estimar que existe litispendencia, y no acumulación de autos. Se ha precisado que no serían "todos" los hechos vinculantes, sino sólo aquellos esenciales, determinantes en la pretensión. Respecto de esto último discrepo, y lo que propongo es que lo realmente vinculante entre un proceso y otro no son ni el derecho alegado, ni la pretensión hecha valer, como tampoco los hechos expuestos. Todos estos elementos son simplemente indiciarios de una posible litispendencia, pero no definitorios, además de la identidad de partes. Lo que sí resulta determinante a la hora de estimar la existencia de procesos conexos es si el "bien de la vida" pretendido en uno y otro proceso son exactamente el mismo.

Antes de seguir, quiero poner un ejemplo respecto de esta especial forma de conexidad. Supongamos que existe un primer proceso entre dos partes, en que el actor expone, como hechos fundantes, haber adquirido un determinado inmueble a un valor sustancialmente inferior al que correspondía según el mercado al momento de la compraventa. Sobre la base de estos hechos, invoca las normas sobre acción rescisoria por lesión enorme del Código Civil (artículo 1888 y siguientes) y solicita concretamente que se anule la compraventa y que el inmueble sea restituido a su patrimonio. En este mismo ejemplo, el demandado comparece al proceso y opone una excepción con buenas posibilidades de éxito, como podría ser la prescripción o la incompetencia del tribunal. El actor, frente a esto, en lugar de perseverar en el proceso en trámite, decide intentar una nueva acción, en 
que "invita", además del primitivo demandado, a un tercer demandado, y en que varía los hechos: ahora dice que su consentimiento al vender adoleció de error a consecuencia del dolo del demandado, en la compraventa del mismo inmueble anterior. Invoca las normas sobre nulidad civil por vicios del consentimiento, con un plazo de prescripción mayor, lo que le permite sortear la prescripción de breve tiempo de la acción rescisoria por lesión enorme. Y lo que pide es que se anule el contrato de compraventa, y como consecuencia, que se efectúen las restituciones mutuas propias de la rescisión, y que el inmueble se restituya a su patrimonio. Queda claro de este ejemplo que ni las partes, ni los hechos expuestos ni la cosa pedida ni la causa de pedir son iguales en uno y en otro proceso. Sin embargo, es poco probable que un juez estime que ambos procesos no estén íntimamente conectados, y no sólo porque se refieren -por ejemplo- al mismo inmueble, mismas partes y mismo contrato, sino sobre todo por la existencia de un proceso anterior en que se trató de lograr exactamente el mismo "bien de la vida", que es la restitución del inmueble. Ese factor procesal es el verdadero factor de conexión, con lo cual se soluciona buena parte de la dilatada discusión sobre factores comunes entre procesos.

El ejemplo recién citado es bastante claro, y he utilizado a propósito un caso en que lo que se pretende es la nulidad de un contrato, que corresponde a lo que Alejandro Romero llama "acciones de condena fundadas en un derecho absoluto"; aunque debo aclarar que este autor, a propósito del estudio de la Ley de Enjuiciamiento Civil española, estima que esos casos son susceptibles de acumulación. Como advierte Romero, se trata de un caso claro porque la sentencia que se dicte en cualquiera de los dos procesos producirá efectos erga omnes. Dicho de otro modo: un contrato no se puede anular dos veces, y una vez declarada la nulidad, vale para todos los futuros demandantes, siendo inoficioso tener que obtener declaraciones adicionales en cada proceso invocando nuevos vicios. Y más aún: como advierte este autor, el debate en este caso no versa tanto sobre la nulidad (que es una simple excusa, a la luz de lo que se invoca en ambos procesos), sino sobre la propiedad de un inmueble, que es, en efecto, un "derecho absoluto". Salvo casos de copropiedad, el ser dueño de una cosa excluye de ese derecho a todas las restantes personas. Esto lleva a Romero a concluir, por ejemplo, que en casos como éste "la alegación que el actor haga en una misma demanda de distintos títulos o causas de adquisición de su derecho absoluto no significa distintas causas de pedir". También señala el caso de "acumulación de acciones condenatorias basadas en derechos reales en las que una misma petición de protección jurisdiccional se justifica en diferentes causas de pedir. El caso más típico es la petición de restitución de la propiedad mediante la interposición de una acción reivindicatoria 
acumulada eventualmente a una acción fundada en un derecho procesal [...] se trata de acciones de condena con causas de pedir distintas y que pueden generar un objeto del proceso complejo, no obstante la unidad de prestación solicitada: la restitución de la cosa”.

\section{Prejudicialidad.}

Respecto de la prejudicialidad, que se estudia en forma muy detallada a propósito de la cosa juzgada, puede definirse como la situación generada cuando un proceso -o lo que en él se resuelva- va a ser un antecedente lógico del segundo proceso (o viceversa). En palabras de Ramos Méndez: "en el momento de dictar sentencia el juez puede encontrarse con determinados problemas o cuestiones jurídicas de cuya resolución previa depende el fallo que ha de dictarse"66; en palabras de Alejandro Romero: "en un sentido restringido, la prejudicialidad trataría de ciertos temas que, por su conexión lógica y jurídica con el objeto del proceso, deben ser decididos por el mismo juez u otro tribunal antes de la decisión del fondo del conflicto sometido a su conocimiento" ${ }^{67}$; o como señala Allorio, que el fallo anterior es simplemente una "exigencia lógica" y un "requisito cronológico" de un juicio futuro o en curso, pero no terminado, expresando un "orden inmodificable de juicios" ${ }^{6}$. Ejemplo clásico de prejudicialidad es la existencia de un primer proceso declarativo acerca de la existencia de una obligación, y un segundo proceso en que se demanda una condena asumiendo como válida y existente la obligación debatida en el primer proceso. En este caso, parece evidente que el segundo proceso no debe resolverse hasta que el primero no se falle, bajo el riesgo de dar origen a dos sentencias contradictorias, en el evento que el primer proceso se falle en contra del actor (se declara inexistente la obligación) y el segundo a favor (se condena a pagar la obligación), por ejemplo; y también para evitar juicios inútiles. Sin embargo, como he acotado, estos riesgos parecen mitigados con la posible invocación de la cosa juzgada. En realidad, lo que logra la litispendencia en estos casos es impedir un mal uso de la administración de justicia e inhibir abusos procesales.

${ }^{66}$ Ramos Méndez, Francisco, Derecho procesal civil (Barcelona, Bosch, 1986), p. 672 .

${ }^{67}$ Romero Seguel, Alejandro, Proceso civil y prejudicialidad administrativa, en Revista de Derecho de la Universidad Católica del Norte, 21 (Chile, 2014) 2, p. 378.

${ }^{68}$ Allorio, Enrico, La cosa juzgada frente a terceros (Madrid, Marcial Pons, 2014), p. 71. 


\section{La litispendencia como solución para la conexidad y prejudicialidad.}

La pregunta que hay que hacerse luego de examinar los casos y ejemplos de conexidad y de prejudicialidad, es si estas hipótesis quedan cubiertas por la litispendencia, o bien, si sólo son reconducibles a la acumulación de autos. Para responder esta pregunta, hay que hacerse cargo de dos cuestiones: $i)$ si la regulación positiva de la litispendencia permite hacer extensiva esta institución a casos en que no existe una perfecta triple identidad legal; y ii) si es así, si existen buenas razones para ello.

Creo que la primera de estas preguntas está respondida en el propio Código: la ley no establece la "camisa de fuerza" de la triple identidad legal, como sí lo hizo, por ejemplo, para la cosa juzgada. Cosa distinta es que la doctrina durante decenios, y la jurisprudencia a coro, hayan repetido una y mil veces que esa identidad legal es un dogma intocable. Principalmente -me imagino- porque es por lejos la solución más fácil. Pero este mito hay que destruirlo, entre otras cosas, porque ni toda la doctrina ni toda la jurisprudencia han recogido ese dogma. Al comienzo he citado la postura de Cristián Maturana, quien citando a Calamandrei ha dicho que el apego estricto a la identidad legal no es necesario respecto de dos juicios "no integrales". El mismo Chiovenda tampoco era un defensor de la estricta triple identidad legal ${ }^{69}$.

Un caso interesante de conexidad entre procesos fue resuelto recientemente por la Primera Sala de la Corte Suprema, en un fallo de 27 de abril de 2011 (rol No 8725/2009), a mi juicio, correctamente. Hoteles de Chile $S$. A. había iniciado un juicio de mera certeza en contra de Metrogas $S$. A. ante el $19^{\circ}$ Juzgado Civil de Santiago, en que solicitaba que se determinara que la demandada no podía variar unilateralmente la forma en que se calculaba el cobro del servicio de suministro de gas. Sin embargo, existía un proceso anterior, ante el $9^{\circ}$ Juzgado Civil de Santiago, iniciado por Metrogas S. A. en contra de Hoteles de Chile S. A., en que la primera había ejercido una acción de cobro de pesos por el suministro de gas prestado entre los años 1999 y 2008, en que por un error, se había cobrado una suma sustancialmente inferior. En el proceso iniciado con posterioridad, la demandada, esto es, Metrogas S. A. opuso la excepción de litispendencia, que fue acogida no sólo en primera instancia, sino que mantenida en las decisiones posteriores de la Corte de Apelaciones de Santiago y de la

${ }^{69}$ Chiovenda, Giuseppe, Principios de derecho procesal civil (Madrid, Santiago, Editorial Reus, 1925), II, pp. 52-53: "poco importa que los dos pleitos procedan de demandas concebidas en forma diferente o en formas de procedimiento distintas: por ej., la acción de declaración positiva produce litispendencia incluso respecto de la demanda de declaración negativa y viceversa; la acción en juicio ordinario produce litispendencia respecto de la acción propuesta en procedimiento excepcional”. 
Corte Suprema. El caso presenta una complejidad evidente que desafía el dogma de la triple identidad legal: las partes, si bien son las mismas, ocupan posiciones procesales opuestas en cada proceso; la cosa pedida y causa de pedir en uno y otro juicio son también completamente distintas. Sin embargo, la litispendencia fue mantenida, afirmando el máximo tribunal que es "irrelevante en cada caso la posición jurídica que asuman en cada proceso" las partes, citando la doctrina de Mario Casarino, y su propia jurisprudencia, por cuanto "no obsta a la cosa juzgada que las partes hayan tenido en los juicios roles distintos de demandante y demandado". Respecto del objeto del proceso, dijo la Corte que las causas de pedir "ambas fluyen de los mismos antecedentes de hecho, repercutiendo recíprocamente lo que haya de resolverse en uno respecto a lo que hubiera que decidirse en el otro de continuarse con la tramitación de ambos juicios", ya que ambos "tienen como basamento el error en el cálculo de la facturación realizada por Metrogas S. A.” Remata la Corte, citándose a sí misma en un fallo de 1926, diciendo que "cuando la ley habla de identidad, dicho término no puede tomarse en un sentido tan absoluto y restringido que importe exigir una igualdad tan completa entre ambas demandas como si una fuera copiada o calcada de la otra".

Esta tendencia del operador jurídico a indagar a fondo lo que hay detrás de los múltiples procesos en trámite, y no conformarse con la sola identidad legal, es en todo caso, de larga data. En el trabajo seminal sobre la litispendencia del procesalista catalán Manuel Serra, del año 1969, ya se recogían varios casos de Tribunal Supremo español en que se dejaba de lado la exigencia de la perfecta identidad entre procesos ${ }^{70}$.

Francisco Málaga también se hace cargo de la tendencia que observó en el Tribunal Supremo español, que precisamente comenzaba a ampliar

${ }^{70}$ Serra, Manuel, Litispendencia, en CastañEda (compilador), Excepciones procesales (Lima, Palestra, 1997), p. 325, según las citas de Morales Godo, Juan, ¿¿Es requisito indispensable la triple identidad para poder hacer uso de la excepción de litispendencia? en Revista Jurídica "Docentia et Investigatio de la Facultad de Derecho de la Universidad Nacional Mayor de San Marcos, 10 N$^{\circ} 2$ (Perú, 2008) 2, p. 63. Este último autor, en todo caso, no parece de acuerdo con las soluciones arribadas en esta jurisprudencia, a pesar de lo sugerente del título de su artículo. Respecto del trabajo de Serra recién citado, valga decir que fue publicado por primera vez en la Revista de Derecho Procesal Iberoamericana del año 1969, en forma casual (supuestamente) junto al trabajo de GutiérRez de CABIEDEs, Eduardo, La litis-pendencia, en Revista de Derecho Procesal Iberoamericana (Buenos Aires, 1969), considerándose hasta hoy cada uno como respuesta del otro. Justo treinta años después de esas monografías, en 1999, vio la luz el exhaustivo trabajo de Málaga, Francisco, La litispendencia (Barcelona, J. M. Bosch, 1999), citado también en este trabajo. 
el rango de acción de la litispendencia a los casos de prejudicialidad ${ }^{71}$. Decía este autor, con razón, que "la exigencia de la triple identidad es muy rígida, de suerte que es difícil que el supuesto de hecho requerido para la exclusión del juicio posterior se verifique en la vida real", y que pese a que la ley española prevé la acumulación como solución para estos casos, ella "no siempre es viable". En razón de ello, dice que "puede afirmarse que existe una auténtica laguna legal para resolver algunos supuestos de simultánea pendencia de juicios conexos por prejudicialidad, lo cual deja las puertas abiertas a la posibilidad de que sobre un mismo asunto recaigan resoluciones incompatibles o contradictorias", agregando que el abarcar estos supuestos de prejudicialidad a los casos de conexidad "no constituye una interpretación contra legem, ya que, como también se ha advertido, el artículo 533, 5a LEC. [hoy derogado] no exige expresamente que los juicios implicados en la situación de doble litispendencia sean idénticos"72. Misma cosa puede decirse respecto de la litispendencia que contempla la ley procesal chilena. Este autor rechaza, por un lado, que la litispendencia sea la solución adecuada a aquellos casos en que el juicio iniciado con posterioridad es el que es prejudicial, pero sí dice que sería la solución idónea -sólo si pudiere suspenderse el proceso posterior, lo que no era posible en la ley española- cuando el juicio prejudicial sea el que se ha iniciado con anterioridad. Como he señalado, no existe una postura definitiva en nuestra doctrina acerca de cuál es el efecto de la litispendencia sobre el juicio posterior, y por lo mismo, nada obsta a que en estos casos en que el juicio posterior, del que el anterior es prejudicial, se suspenda mientras no se resuelva el antecedente lógico que es necesario para su resolución. Hay que agregar que el propio Gutiérrez de Cabiedes, en su obra de 1969 ya ampliaba la litispendencia a los presupuestos de prejudicialidad ${ }^{73}$, entre otros autores españoles de la misma tendencia ${ }^{74}$, bajo la antigua Ley de Enjuiciamiento Civil. Este problema vino a solucionarse en el artículo 43 de la nueva ley de enjuiciamiento del año 2000, descartando la litispendencia como solución, sin perjuicio de lo cual el Tribunal Supremo español la siguió aplicando a casos de prejudicialidad ${ }^{75}$.

${ }^{71}$ Málaga, cit. (n. 1), pp. 553-560.

${ }^{72}$ Málaga, cit. (n. 1), pp. 560-561.

${ }^{73}$ GutiérRez de Cabiedes, cit. (n. 70), p. 630.

${ }^{74}$ Cordón Moreno, cit. (n. 48), p. 58: "en ocasiones, sin embargo, el propio Tribunal Supremo, desnaturalizando en cierta medida el significado de la excepción, ha dulcificado la exigencia de la identidad, elevando a primer plano otros principios, como son la necesidad de evitar que se divida la continencia de la causa o que se dicten sentencias contradictorias y, en ocasiones, el deseo de resolver en justicia”.

${ }^{75}$ Reynal Querol, Núria, Inadecuación de la litispendencia para resolver supuestos 
Queda por responder la segunda pregunta que hacía al comienzo: ¿hay buenas razones para extender la litispendencia a los casos de juicios conexos y prejudiciales? De lo recogido en la experiencia española, cuya ley procesal civil tenía la misma laguna que se advierte en el Código chileno, no queda sino concluir que la litispendencia es efectivamente una solución idónea para casos de prejudicialidad y conexidad, no sólo por las razones apuntadas de seguridad jurídica y de evitar juicios inútiles y decisiones contradictorias (objetivos que de cualquier forma quedarán cautelados por la cosa juzgada), sino principalmente teniendo en cuenta el abuso procesal o la mala fe de los litigantes en iniciar procesos en paralelo, constituyéndose así la litispendencia en un resguardo del deber de congruencia y buena fe que debe existir en todo juicio jurisdiccional.

\section{CONCLUSIONES}

$1^{\circ}$ La legislación chilena sólo enuncia la litispendencia, quedando la regulación sobre sus requisitos y efectos a cargo de la doctrina y jurisprudencia, las que mayoritariamente han estimado que debe concurrir la triple identidad legal de partes, cosa pedida y causa de pedir entre los procesos. Si bien la doctrina no es explícita respecto del efecto que genera la sentencia que acoge la litispendencia, en este trabajo se sostiene que es la suspensión del segundo proceso mientras no finalice el primero por sentencia definitiva firme, en cuyo caso, se producirá el efecto de cosa juzgada.

$2^{\circ} \mathrm{La}$ litispendencia no corresponde a un remedio frente al llamado concurso de acciones y de normas, concurso que en cualquier caso parecen manifestaciones consustanciales a la garantía constitucionalmente consagrada de la tutela judicial efectiva.

$3^{\circ}$ Sin perjuicio de que la litispendencia comparte varios de los fines de la cosa juzgada, como son la evitación de sentencias contradictorias y juicios inútiles, la continencia y unicidad de los procesos y la economía procesal, la litispendencia tiene una finalidad particular, que es sancionar procesalmente la mala fe del litigante que inicia varios procesos coetáneamente, sanción que será preferible en esos casos frente a la simple acumulación de autos, cuyos presupuestos son coincidentes con la litispendencia.

$4^{\circ} \mathrm{La}$ litispendencia no sólo procede frente a litigios en que existe perfecta triple identidad legal de partes, cosa pedida y causa de pedir, sino también frente a ciertos casos de litigios conexos y prejudiciales, como ha tenido la oportunidad de manifestarlo la doctrina y jurisprudencia.

de prejudicialidad. Comentario a la sentencia del Tribunal Supremo de 17 de abril de 2007 (RJ 2007/4188), en Ius Labor (Barcelona, 2008). 


\section{BiBLIOGRAFÍA}

Alessandri Rodríguez, Arturo, De la responsabilidad extra-contractual en el derecho civil chileno ([reimpresión] Santiago, Editorial Jurídica Ediar ConoSur, 1983).

Allorio, Enrico, La cosa juzgada frente a terceros (Madrid, Marcial Pons, 2014).

Alonso Traviesa, María Teresa, El problema de la concurrencia de responsabilidades (Santiago, LexisNexis , 2006).

Alsina, Hugo, Tratado teórico de derecho procesal civil y comercial (Buenos Aires, Ediar, 1957), II.

Anabalón, Carlos, Tratado práctico de derecho procesal civil chileno, III: El juicio ordinario de mayor cuantía (Santiago, Arancibia Hermanos, 1963).

Anabalón, Carlos, Tratado práctico de derecho procesal civil chileno, III: Disposiciones Comunes a todo procedimiento y de las cuestiones de competencia (Concepción, Escuela Tipográfica Salesiana, 1966).

Avsolomovich, Alex - LüHrs, Germán - Noguera, Ernesto, Nociones de derecho procesal (Santiago, Editorial Jurídica de Chile, 1966).

Barros, Enrique, Tratado de responsabilidad extracontractual (Santiago, Editorial Jurídica de Chile, 2008).

Benavente, Darío, Derecho procesal civil. Juicio ordinario y recursos procesales ( $5^{\text {a }}$ edición revisada por Juan Colombo Campbell, Santiago, Editorial Jurídica de Chile, 2004).

Bordalí, Andrés, El derecho fundamental de acción: un intento de configuración en el orden constitucional chileno, en Revista de Derecho y Jurisprudencia, 97 (Santiago, 2000) 3.

Calamandrei, Piero, Estudios sobre el proceso civil (Buenos Aire, Editorial Bibliográfica Argentina, 1945).

Calamandrei, Piero, Instituciones de derecho procesal civil (Buenos Aires, Ediciones Jurídicas Europa-América, 1986), II.

Carnelutti, Francesco, Instituciones del proceso civil (Buenos Aires, Ediciones Jurídicas Europa-América, 1950), I.

CARRETTA, Francesco, La coherencia en el proceso civil. Imperativo conductual y decisional desde la buena fe (casos y jurisprudencia) (Santiago, Thomson Reuters, 2013).

CAsArino, Mario, Manual de derecho procesal. Derecho procesal civil (Santiago, Editorial Jurídica de Chile, 2009), IV.

Cordón Moreno, Faustino, La excepción de litispendencia. Comentario a la STS de 25 de febrero de 1992, Repertorio de Jurisprudencia Aranzadi 1552, en Revista Jurídica de Navarra, 15 (1993).

Chiovenda, Giuseppe, Principios de derecho procesal civil (Madrid, Reus, 1925), II.

Corral, Hernán, Lecciones de responsabilidad extracontractual (Santiago, LegalPublishing, 2013).

Cury, Enrique, en Derecho penal. Parte general (Santisgo, Ediciones Universidad Católica de Chile, 2009).

d'Ors, Álvaro, Derecho privado romano (Pamplona, Ediciones Universidad de Navarra, 1981).

De la Oliva Santos, Andrés, Objeto del proceso y cosa juzgada en el proceso civil (Navarra, Thomson- Civitas, 2005).

EKDAHL, María Fernanda, La doctrina de los actos propios. El deber jurídico de no contrariar conductas propias pasadas (Santiago, Editorial Jurídica de Chile, 1989), 
Equipo Consultor Facultad de Economía y Empresa Universidad Diego Portales, Tasas judiciales en la experiencia comparada (Santiago, 2012).

Goldschmidt, James, Derecho procesal civil (Barcelona, Labor, 1936),

GonZÁlez Álvarez, Roberto, El principio fundamental de acción. Nuevo paradigma de la ciencia procesal, en Ars Boni et Aequi, 7 (Santiago, 2011) 2.

GuASP, Jaime, La pretensión procesal (Madrid, Civitas, 1985).

GutiérRez de Cabiedes, Eduardo, La litis-pendencia, en Revista de Derecho Procesal Iberoamericana (Buenos Aires, 1969).

Guzmán Santa Cruz, Roberto, Repertorio de conceptos de derecho procesal civil (Santiago, Carlos E. Gibbs, 1966).

HunTer, Iván, El poder del juez para rechazar "in limine" la demanda por manifiesta falta de fundamento, en Ius et Praxis, 15 (Talca, 2009) 2.

HunTER, Iván, La aplicación judicial del derecho en el proceso civil. Doctrina, jurisprudencia y derecho comparado (Santiago, Thomson Reuters, 2015).

Liebman, Tulio Enrico, Eficacia y autoridad de la sentencia y otros estudios sobre la cosa juzgada (Buenos Aires, Ediar, 1946).

Málaga, Francisco, La litispendencia (Barcelona, J. M. Bosch, 1999).

Marinoni, Luiz Guilherme - Pérez Ragone, Álvaro - Núñez OJedA, Raúl, Fundamentos del proceso civil. Hacia una teoría de la adjudicación (Santiago, LegalPublishing, 2010).

Maturana, Cristián, Relación entre la litispendencia, la acumulación de autos y la cosa juzgada (Memoria para optar al grado de licenciado en ciencias jurídicas y sociales de la U. de Chile, 1982).

Mir, Santiago, Derecho penal. Parte general (Barcelona, Reppertor, 2012).

Monroy Gálvez, Juan - Monroy Palacios, Juan José, Las relaciones entre jueces, partes y abogados en el proceso civil peruano, en De LA Oliva y otros (coordinador), Proceso civil. Hacia una nueva justicia civil (Santiago, Editorial Jurídica de Chile, 2007).

Morales Godo, Juan, ¿Es requisito indispensable la triple identidad para poder hacer uso de la excepción de litispendencia?, en Revista Jurídica "Docentia et Investigatio de la Facultad de Derecho de la Universidad Nacional Mayor de San Marcos, $10 \mathrm{~N}$ (Lima, 2008) 2.

Muther, Theodor, Zur Lehre von der Römischen Actio, dem heutigen Klagrecht, der Litiscontestatio und der Singularsuccession in Obligationen. Eine Kritik des Winscheidschen Buchs, en Die action des römischen Civilrechts, vom Standpunkte des heutigen Rechts (Erlangen, Andreas Deichert, 1857).

NiEva, Jordi, La cosa juzgada (Barcelona, Atelier Derecho, 2006).

Nieva, Jordi, Derecho procesal, I: Introducción (Madrid, Marcial Pons, 2014).

ORMAZÁBAL, Guillermo, en "Iura novit curia". La vinculación del juez a la calificación jurídica de la demanda (Madrid, Marcial Pons, 2007).

Prieto Castro, Leonardo, Derecho procesal civil (Madrid, Aranzadi, 1982), I.

Ramos Méndez, Francisco, Derecho procesal civil (Barcelona, Bosch, 1986).

Redenti, Enrico, Derecho procesal civil (Buenos Aires, Ediciones Jurídicas EuropaAmérica, 1957).

Reynal Querol, Núria, Inadecuación de la litispendencia para resolver supuestos de prejudicialidad. Comentario a la sentencia del Tribunal Supremo de 17 de abril de 2007 (RJ 2007/4188) en IusLabor (Barcelona, 2008).

Rodríguez Papic, Ignacio, Procedimiento civil. Juicio ordinario de mayor cuantía (Santiago, Editorial Jurídica de Chile, 2010). 
ROMERo, Sophia, Concurso de normas y concurso de acciones en el derecho procesal civil chileno, en Ius et Praxis, 19 (Talca, 2013) 2.

Romero Seguel, Alejandro, La acumulación de acciones en el derecho procesal español (Madrid, Cedecs, 1999).

Romero Seguel, Alejandro, El principio de la buena fe procesal y su desarrollo en la jurisprudencia, a la luz de la doctrina de los actos propios, en Revista Chilena de Derecho, 30 (Santiago, 2003).

Romero Seguel, Alejandro, Curso de derecho procesal civil (Santiago, Editorial Jurídica de Chile, 2012).

Romero Seguel, Alejandro, Curso de derecho procesal Civil (Santiago, Editorial Thomson Reuters, 2014), I.

Romero Seguel, Alejandro, Proceso civil y prejudicialidad administrativa, en Revista de Derecho de la Universidad Católica del Norte, 21 (Coquimbo, 2014) 2.

Rosenberg, Leo, Tratado de derecho procesal civil (Buenos Aires, EJEA, 1955), II.

SERRA, Manuel, Litispendencia, en CASTAÑEDA (compilador), Excepciones procesales (Lima, Palestra, 1997).

SolÉ, Jaume, Convergencias y divergencias entre los procesos civil y penal. Perspectiva del abogado civilista, en ARMENTA (coordinador), La convergencia entre el proceso civil y penal ¿Una dirección adecuada? (Madrid, Marcial Pons, 2013).

Stoehrel, Carlos Alberto, De las disposiciones comunes a todo procedimiento y de los incidentes ( 6 a edición revisada y actualizada por Davor Harasic Yaksic, Santiago, Editorial Jurídica de Chile, 2011).

Tavolari, Pía, El abuso en el proceso ("Prólogo" de Manuel Ortells Ramos, Santiago, Ediciones Congreso, 2004).

Vegas Torres, Jaime, La eficacia excluyente de la litispendencia, en Revista Electrónica del Departamento de Derecho de la Universidad de La Rioja (Logroño, 2002).

VON SAVIGNY, Friedrich, System des heutigen römischen Rechts, en Problemgeschichte des Verhältnisses von formellen und materiellem Recht (Berlin, Duncker \& Humboldt, 1996).

WindscheID, Bernhard, Die Action des römischen Civilrechts, vom Standpunkte des heutigen Rechts [Düsseldorf, Julius Bideus, 1856; traducción al español como La "actio" del derecho civil romano desde el punto de vista del derecho actual, en el volumen Polémica sobre la "actio" (Buenos Aires, EJEA, 1974)].

YZQUiERdo TOlSADA, Mariano, Sistema de responsabilidad civil extracontractual (Madrid, Dykinson, 2001). 
